Dr. Juan José Romero Álvarez

Universidad Francisco de Vitoria

@ juanjo695@yahoo.es

Dr. Juan de Dios Molina Martín

Profesor de Criminología, Universidad Francisco de Vitoria. Jefe del Centro de Salud Mental de Villaverde. Hospital 12 de Octubre
Recibido / Received 18 de diciembre de 2018

- Aceptado / Acepted 1 de febrero de 2019

- Páginas / Pages De la 81 a la 126

- ISSN: 2531-0054

@ jmolinamar@hotmail.com

\title{
Esquizofrenia y delincuencia: análisis de la jurisprudencia del Tribunal Supremo entre 2008 y 2018
}

Schizophrenia and delinquency: Analysis of the jurisprudence of the Supreme Court between 2008 and 2018

El riesgo de violencia en esquizofrenia se ve incrementado por factores como el consumo de drogas, la falta de tratamiento, la marginación social y laboral o el bajo nivel educativo. En esta investigación se lleva a cabo un análisis de la jurisprudencia del Tribunal Supremo con el fin de determinar, por un lado, qué factores de riesgo reconocidos en la literatura científica tienen un reflejo en la doctrina penal y, por otro, el tratamiento de la imputabilidad de estas personas efectuado por el Alto Tribunal. Se analiza también la presencia del tratamiento ambulatorio involuntario como medida de seguridad no privativa de libertad en estos casos y se incluye una entrevista al magistrado de la Audiencia Nacional Fermín Javier Echarri Casi. Como resultado de la revisión se obtiene que la esquizofrenia paranoide, la ausencia de tratamiento y el consumo de drogas son los factores de riesgo con más presencia en las sentencias analizadas; que los criterios que abordan la imputabilidad se basan en el nexo causal y en la afectación de las capacidades, dando como resultado la aplicación de los artículos del Código Penal 20.1, 21.1 o 21.7, según sea el caso. Y que el Tribunal Supremo nunca establece el tratamiento ambulatorio involuntario como medida de seguridad no privativa de libertad.

PALABRAS CLAVE: esquizofrenia, Tribunal Supremo, factores de riesgo, imputabilidad, tratamiento ambulatorio involuntario.

Violence risk in schizophrenia increases due to factors such as substance abuse, deficiencies in the treatment, social and occupational marginalization or low educational level. Through the analysis of the jurisprudence of the Supreme Court, this investigation attempts to achieve three objectives. In the first place, to recognize the risk factors acknowledged in the scientific literature that appear in the judicial doctrine. Secondly, to ascertain the criteria about the imputability of schizophrenic people. Finally, to analyze the presence of the involuntary outpatient treatment as a non custodial security measure. An interview to Fermín Javier Echarri Casi, magistrate of the National Audience, is also included. Paranoid schizophrenia, substance abuse and deficiencies in the treatment are the most significant risk factors that appear in the analyzed sentences. Also, the criteria about the imputability is based on the impairment of capacities and the causal 
nexus, which leads to the application of the articles 20.1,21.1 and 21.7 of the Criminal Code according to the case. Finally, involuntary outpatient treatment is never settled in the Supreme Court sentences as a non custodial security measure.

KEYWORDS: schizophrenia, Supreme Court, risk factors, imputability, involuntary outpacient treatment.

\section{Justificación y relevancia}

Las enfermedades mentales siempre han sido percibidas como fuente de conflicto y violencia, visión que se ha visto reforzada por los medios de comunicación que ponen el foco sobre los casos más mediáticos (Stuart, 2003). Es cierto que un padecimiento de estas características no está exento de problemas y complicaciones de todo tipo, incluidos los casos más extremos. Sin embargo, esta es una cuestión que depende de muchos factores que rodean a la propia enfermedad mental y que, por tanto, no es consecuencia única de la misma.

En el caso concreto de la esquizofrenia, la errónea interpretación del entorno que esta provoca puede llevar a los enfermos mentales a reaccionar de manera desproporcionada y violenta ante determinadas situaciones (Arbach y Pueyo, 2007). La realidad es que el simple padecimiento mental no les lleva a ser más violentos que la población general. Son el resto de factores que rodean esta enfermedad los que elevan el riesgo y pueden llevar incluso a la comisión delictiva. Algunos de ellos son el consumo de drogas, la marginación social o la falta de tratamiento adecuado y el incumplimiento del mismo (Esbec y Echeburúa, 2016).

Es de vital importancia, por tanto, el conocimiento de estos aspectos. Cuando el enfermo mental se ve inmerso en un proceso penal, no basta con el mero conocimiento de las cuestiones médicas, sino que estas deben ser integradas en la materia jurídica. De esta manera, se alcanza una comprensión multidisciplinar de la comisión delictiva en enfermos de esquizofrenia.

Con el fin de alcanzar el mencionado conocimiento, en este trabajo se revisará, por un lado, la literatura científica referente a la esquizofrenia (concepto, diagnóstico, tipos, etapas, comorbilidades y tratamiento). Por otro, se tratará el tema de la incidencia de dicha enfermedad en comportamientos violentos y comisión de delitos, haciendo mención a algunos de los estudios más relevantes sobre esta materia. Finalmente, se expondrá la norma jurídica aplicable a este tipo de personas (imputabilidad y medidas de seguridad).

Una vez expuesto el marco teórico, se realizará un análisis jurisprudencial de las sentencias del Tribunal Supremo de los últimos 10 años, así como de las sentencias de primera instancia. Se contrastarán los conocimientos expuestos en la primera parte del trabajo con la doctrina penal, con el fin de aportar un valor científico y teórico a este tema.

En concreto, se buscará la comparativa entre tres cuestiones principales: la presencia en las sentencias de los factores que elevan el riesgo de violencia en esquizofrénicos, el tratamiento jurisprudencial en cuanto a imputabilidad y la aplicación del tratamiento ambulatorio involuntario como medida de seguridad no privativa de libertad.

\section{Introducción y marco teórico}

\subsection{Introducción a la esquizofrenia}

Antes de hablar de la esquizofrenia es necesario hacer una aproximación al concepto de psicosis. Esta hace referencia a diversas alteraciones mentales que causan un grave deterioro 
de la evaluación de la realidad en un individuo que no es consciente de la naturaleza patológica de este fenómeno. Los síntomas más conocidos son las alucinaciones y delirios (el resto se exponen más adelante), y en función de la intensidad y cantidad de dichos síntomas se establecen los distintos trastornos psicóticos que existen (Molina, 2013; DSM-V): esquizofrenia, trastorno esquizoafectivo, trastorno esquizofreniforme, trastorno delirante, trastorno psicótico breve y trastorno esquizotípico.

La esquizofrenia sería el trastorno más grave de todos ellos, ya sea por la intensidad o por la duración de los síntomas. Estos últimos no son patognomónicos (que por sí mismos aseguren la presencia de la enfermedad), por lo que a la hora de emitir un diagnóstico se atiende a criterios clínicos. Dichos criterios aparecen en los sistemas diagnósticos de clasificación, y los más importantes son la Clasificación Estadística Internacional de Enfermedades (CIE) y el Manual Diagnóstico y Estadístico de los Trastornos Mentales (DSM) (Molina, 2013).

Se estima que esta enfermedad la padece entre un $0,5 \%$ y un $1 \%$ de la población (Goldner, Hsu, Waraich y Somers, 2002); es el trastorno mental más costoso, ya que un 2,5\% del gasto sanitario se destina a la misma (Baldwin, Browne y Scully, 2005). La genética juega un papel clave en su aparición. Diversos estudios estiman en un $65 \%$ la probabilidad de padecer esquizofrenia ligada a componentes hereditarios, además del aumento de entre un $5 \%$ y un $10 \%$ del riesgo de sufrirla si algún familiar de primer grado la tiene (Kendler y Diehl, 1995). Por su parte, se han estudiado también diversos factores de riesgo no genéticos, como el hecho de nacer a finales de invierno o principios de primavera (Mortensen, Pederson y Westergaard, 1999), habitar en zonas urbanas (McGrath et al., 2004) e, incluso, el consumo frecuente de cannabis durante la adolescencia (Arseneault et al., 2002).

\subsubsection{Síntomas}

Hoy en día existe un cierto consenso acerca de las tres grandes categorías de síntomas psicóticos de la esquizofrenia (Molina, 2013). La clasificación completa es la siguiente (Carrasco y Maza, 2010; DSM-IV):

\section{a) Síntomas positivos}

Son un exceso o distorsión de las funciones normales que se añaden al estado mental previo a la psicosis. Dentro de estos encontraríamos:

- Ideas delirantes: se definen como una interpretación errónea de la realidad, que provoca que se tengan como verdaderas ideas falsas, con una intensa convicción subjetiva. Dependiendo de su cronicidad e intensidad, pueden llevar al que las padece a erigir su vida en torno a un sistema de falsas creencias, muchas veces incorregibles e ininfluenciables.

Según cómo se formen, se distinguen dos tipos de ideas delirantes:

- Primarias: por un lado pueden surgir de manera completamente original del interior del sujeto (de lo endógeno), dando lugar a comportamientos anómalos que pueden sorprender incluso al que los padece. Por otra parte, pueden conformarse más lentamente a partir de percepciones correctas de la realidad que, sin embargo, son erróneamente interpretadas. 
- Secundarias: surgen a raíz de diversos procesos psíquicos, como alteraciones del nivel de conciencia, consumo e intoxicaciones por sustancias o cambios en el estado de ánimo. Son más comprensibles que las primeras, no se cronifican, pueden ser de breve duración, además de ser influenciables y corregibles.

En función de su contenido, existen:

- Delirios de persecución: el paciente tiene el convencimiento de que alguna persona o grupo le está espiando, acosando, engañando o siguiendo. Pueden producirse agresiones inmotivadas contra desconocidos.

- Delirios de perjuicio: el sujeto piensa que los demás le están perjudicando de alguna manera por envidia, ya sea en el entorno laboral o en el propio vecindario.

- Delirios de influencia: el que los padece piensa que existe una fuerza misteriosa ejercida por alguien en la distancia que puede llegar a controlar sus actos y pensamientos.

- Delirios autorreferenciales: el sujeto se siente el centro de atención, tanto de la gente de su alrededor como de los medios de comunicación. Piensa que le observan y comentan sobre él.

- Delirios de celos: convencimiento firme de que la pareja está siendo infiel. Pueden llevar a conductas violentas contra el supuesto amante.

- Delirios de grandeza: el paciente se siente superior, poderoso o rico, y en ocasiones puede identificarse con algún personaje histórico. En estos casos el comportamiento normal no tiene por qué verse alterado.

- Delirio de ruina: en el que sufre este delirio surge la idea de estar arruinándose, aunque se le enseñen los datos de su cuenta bancaria. Más que conductas violentas hacia los demás, pueden llegar a producirse conductas suicidas.

- Delirios religiosos: los pacientes se sienten portadores de un mensaje divino, la reencarnación de Jesús o que su misión en el mundo es la lucha contra el mal, entre otras cosas. Por ejemplo, pueden llegar a agredir a personas que consideran como el demonio o Satán, y tras ello creerán que merecen agradecimiento universal por haber salvado al mundo.

- Delirio pleitista: se manifiesta en la tendencia del paciente a emprender acciones legales constantemente, ante supuestas injusticias que le afectan. Puede llegar a tomarse la justicia por su mano a través de acciones violentas.

- Delirios hipocondríacos, de culpa o de negación: son menos habituales.

- Alucinaciones: son percepciones erróneas de la realidad que producen una convincente sensación de realismo a través de los sentidos, cuando realmente estos no han sido externamente estimulados. Se clasifican según la modalidad sensorial y complejidad en:

- Alucinaciones auditivas: son las más frecuentes. Las más simples consisten en ruidos, pitidos o zumbidos, mientras que las de mayor complejidad son percibidas como voces, animales o música. Dichas voces pueden ser tranquilizantes y agradables. Sin embargo, son especialmente características de la esquizofrenia las voces peyorativas o amenazantes, que conversan entre ellas o comentan continuamente el comportamiento y las acciones del sujeto. Ante alucinaciones imperativas, el pa- 
ciente se siente impulsado a cumplir con las órdenes, haciéndolo muchas veces de manera automática, irreflexiva y brutal.

- Alucinaciones visuales: pueden ir desde meros destellos, halos luminosos o llamas hasta figuras geométricas o personas en movimiento. Son habitualmente experimentadas con desagrado.

- Alucinaciones olfativas: se perciben olores raros y desagradables. Se puede pensar que vienen del exterior y tender a aislarse cerrando puertas y ventanas, o que vienen de uno mismo.

- Alucinaciones gustativas: en este caso los sabores percibidos son también desagradables y pueden llevar a la idea de que es debido a la presencia de sustancias o venenos en la comida.

- Alucinaciones táctiles: pueden ser percibidas en la superficie exterior del cuerpo o en el interior (alucinaciones cenestésicas). Ejemplos son el sentir pellizcos, calor o frío, descargas eléctricas, tirones del brazo, invasión del cuerpo e incluso violaciones al dormir. Los casos más graves pueden motivar denuncias por malos tratos o violación o, directamente, agresiones contra personas que el paciente cree que son responsables de sus sensaciones. También se pueden producir autolesiones.

\section{b) Síntomas negativos}

Son un déficit de las facultades normales previas a la psicosis. Dentro de esta categoría se encuentran:

- Aplanamiento afectivo: marcada disminución de la expresividad emocional, como inmovilidad de las expresiones faciales, escaso contacto visual y reducción del lenguaje corporal. Este síntoma se asocia a la anhedonia, caracterizada por la dificultad para experimentar placer.

- Alogia: descenso de la fluidez y aumento de la pobreza del habla.

- Abulia: falta de motivación. El paciente es incapaz de iniciar y mantener actividades dirigidas a un fin.

- Apatía: desinterés por las actividades cotidianas.

\section{c) Síntomas desorganizados}

Aquí se incluyen diversos síntomas que no encajan en las categorías anteriores y de frecuente presencia en la esquizofrenia:

- Lenguaje desorganizado: pérdida de asociaciones (perder el hilo), tangencialidad (respuestas con poca o ninguna relación con el tema de la conversación) o incoherencia (el lenguaje puede llegar a ser incomprensible).

- Comportamiento desorganizado: falta de higiene, vestimenta extravagante, desorden o comportamiento inadecuado, entre otros. Muchas veces vienen motivados por ideas delirantes.

- Catatonía: aquí se engloban distintas alteraciones motoras, como la falta de reactividad y atención al entorno (estupor catatónico), rigidez y resistencia en la postura (rigidez catatónica), resistencia activa a las órdenes e intentos de ser movido (negativismo cata- 
tónico), asumir posturas inapropiadas o extrañas (posturas catatónicas) o una actividad motora excesiva sin propósito ni estímulo que la provoque (agitación catatónica).

- Ecolalia: pensamiento repetitivo.

- Ecopraxia: repetición de palabras imitando a otra persona.

\subsubsection{Tipos}

Existen diversos subtipos de esquizofrenia en función de los síntomas característicos que se presenten; poseen, además, una evolución, pronóstico, tratamiento y comportamiento delictivo diferente (DSM-IV; Carrasco y Maza, 2010).

\section{a) Esquizofrenia paranoide}

Es la que se ve involucrada en delitos violentos con más frecuencia. Se caracteriza por el predominio de síntomas positivos como ideas delirantes y alucinaciones auditivas, además de una relativa conservación de las capacidades cognoscitivas. Tampoco se encuentran manifestaciones importantes de conductas desorganizadas o catatónicas ni alteraciones del lenguaje. Suele tener un pronóstico mejor que otros tipos de esquizofrenia, sobre todo en lo que respecta a la vida laboral e independiente. Los delirios persecutorios pueden predisponer al paciente a conductas suicidas, mientras que una combinación de estos con ideas de grandeza e ira pueden desencadenar actos violentos. Algunos síntomas asociados a este subtipo son la mencionada ira, ansiedad, retraimiento y tendencia a discutir.

\section{b) Esquizofrenia desorganizada o hebefrénica}

Predominan síntomas desorganizados, como lenguaje desorganizado con pérdida de asociaciones e incoherencias, afectividad aplanada o inapropiada y una disfuncionalidad para las tareas cotidianas. También puede haber delirios y alucinaciones no estructurados. Los sujetos que la padecen presentan una disminución del rendimiento en general, debido a un empobrecimiento de la personalidad originada por esta enfermedad. Muchos de ellos están ingresados en hospitales psiquiátricos debido a este deterioro. Por tanto se ven pocas veces involucrados en la comisión de delitos, y cuando lo hacen es a causa de conductas impulsivas.

\section{c) Esquizofrenia catatónica}

En este subtipo de esquizofrenia predominan las alteraciones motoras. Son frecuentes las crisis de agitación psicomotriz, inmovilidad, negativismo, mutismo, ecolalia o ecopraxia, entre otras. Lo más habitual es que la actividad motora se vea disminuida, y se dan casos en los que el paciente permanece en la misma postura durante horas o incluso días. Los actos violentos no serían habituales, pero pueden llegar a darse en forma de conductas violentas, impulsivas e inesperadas, sin ninguna motivación ni relación a elementos externos, y que no serían más que otra manifestación de esta enfermedad.

\section{d) Esquizofrenia indiferenciada}

Esta categoría se utiliza con la única finalidad de clasificación en el ámbito clínico, aunque pueden aparecer referencias a la misma en informes forenses. Se encuadran aquí todos aquellos 
casos que, presentando síntomas positivos y desorganizados, no cumplen los requisitos diagnósticos para ser considerados como esquizofrenia paranoide, desorganizada o catatónica.

\section{e) Esquizofrenia residual}

Se caracteriza por la ausencia de síntomas positivos o por su presencia de manera muy atenuada, y por la presencia de síntomas negativos, como la alogia, abulia, aplanamiento afectivo, además de una disminución del rendimiento intelectual. Estas manifestaciones negativas no solo se deben a la propia enfermedad, sino también a efectos de los medicamentos y a la falta de estímulos a la que se ve sometido el paciente al pasar mucho tiempo aislado. Por todo ello este subtipo es considerado como una verdadera secuela de la esquizofrenia. En cuanto a las actividades delictivas, las disminuciones afectivas y de la voluntad hacen que estos pacientes sean muy fáciles de manipular y puedan verse envueltos en situaciones de tráfico de drogas y de colaboración y participación en robos. Los actos más graves se corresponderían con estados de esta enfermedad más leves, donde aún se conservan las capacidades necesarias para ejecutarlos.

En 2013 se publicó el DSM-V, el cual introdujo varios cambios con respecto a la edición anterior. Uno de los más significativos fue la eliminación de los subtipos de esquizofrenia citados en este apartado debido a su baja fiabilidad, validez y estabilidad diagnóstica (APA, 2013). En su lugar, la sección III del nuevo manual establece un modelo de evaluación dimensional basado en ocho ítems que miden la gravedad de los síntomas. Estos son (DSM-V): alucinaciones, delirios, lenguaje desorganizado, comportamiento motor anormal, síntomas negativos, deterioro cognitivo, depresión y manía.

\subsubsection{Etapas}

La American Psychiatric Association (APA, 2000) ha establecido cuatro fases diferenciadas a lo largo de la evolución de la esquizofrenia, aunque admitiendo que no existen límites bien definidos. Estas serían:

\section{a) Fase prodrómica}

Periodo durante el cual se van desarrollando diferentes síntomas en el año previo al inicio de la siguiente fase, denominada aguda, y que se estima afecta al $80 \%$ de los pacientes. Algunos de dichos síntomas pueden ser: comportamiento extraño, falta de motivación, aislamiento social o descuido de la higiene personal. Puede durar desde días a varias semanas.

\section{b) Fase aguda}

En esta fase se manifiestan los síntomas más graves: delirios, alucinaciones y pensamiento y lenguaje desorganizados. El paciente no tiene conciencia de su enfermedad ni está capacitado para cuidar de sí mismo.

\section{c) Fase de estabilización}

Comienza en el momento en que los síntomas agudos de la fase anterior empiezan a disminuir en duración, intensidad y frecuencia. 


\section{d) Fase estable}

La sintomatología psicótica se muestra bajo control o muy disminuida en comparación con fases anteriores. Por su parte pueden surgir otro tipo de síntomas no característicos de la psicosis, como depresión, trastornos alimenticios, problemas del sueño o ansiedad. Esta fase podría ser o bien el final de la crisis de la enfermedad o bien representar un periodo intermedio si a este le siguen otras fases agudas.

Más recientemente se ha propuesto un modelo similar pero que integra, además de la sintomatología psicótica, el curso y evolución que pueden presentar los pacientes en cada fase y el tratamiento que deben seguir (Ruiz-Irondo, Salaberría y Echeburúa, 2013). Este pasaría a denominarse modelo de los estadios clínicos y, según la revisión llevada a cabo por estos autores, dicho modelo se dividiría en las siguientes fases:

\section{a) Fase prodrómica}

Fase durante la cual el paciente puede presentar síntomas inespecíficos, tener un historial familiar de esquizofrenia y observar un descenso a nivel funcional, aunque no se cumplan los criterios diagnósticos de esquizofrenia. El objetivo, por tanto, sería evitar la transición a la psicosis, por medio de antipsicóticos en dosis bajas y terapia psicológica, que servirá para aumentar la conciencia de enfermedad y las estrategias de afrontamiento, reducir el estrés y el riesgo de inicio de otras comorbilidades y aumentar la autoestima. En los nuevos estudios llevados a cabo siguiendo este modelo se encontró que el $40 \%$ de los casos de alto riesgo evolucionaron a la psicosis en el periodo de un año.

\section{b) Fase aguda}

En esta fase aparecen síntomas positivos y desorganizados de forma grave y los pacientes tienen su primer contacto con los servicios de salud mental. El objetivo principal es la correcta adherencia al tratamiento, reduciendo los efectos adversos del mismo, a través de medicación antipsicótica en dosis óptimas, junto con terapias que ayuden al enfermo a aumentar su conciencia de enfermedad y a lidiar con las alucinaciones y delirios. Una vez que se estabilizan los síntomas psicóticos se entra en la fase crítica. Sin embargo, un $20 \%$ de los pacientes acaba derivando en una forma crónica de la enfermedad.

\section{c) Fase crítica}

Pueden surgir síntomas positivos entre moderados y graves, síntomas negativos moderados, deterioro cognitivo y aislamiento social. El empeoramiento de estos dos últimos es el que impide la vuelta a la fase prodrómica. Los objetivos son el cumplimiento del tratamiento para evitar nuevos síntomas y la readaptación social y laboral, evitando recaídas, abandonos y suicidios, cuyo riesgo de incidencia aumenta considerablemente en esta etapa. Se debe continuar además con terapias psicológicas orientadas a los síntomas psicóticos. La evolución puede ir desde una remisión o mantenimiento del estado actual hasta el paso a una fase crónica.

\section{d) Fase subcrónica}

Se producen numerosas recaídas con presencia de síntomas psicóticos atenuados, y es evidente el deterioro físico y psicológico. Los objetivos y tratamientos son similares a los de 
la etapa anterior, pero con mayor incidencia en la intermodalidad, ya que en este punto el deterioro afecta a todas las esferas vitales de los enfermos. Se pueden seguir produciendo recaídas, e incluso pasar a una fase crónica.

\section{e) Fase crónica}

Se diagnostica cuando han pasado al menos cinco años desde el inicio de la enfermedad, se han sucedido varias recaídas, hay una mala evolución general y dificultades para retomar las actividades cotidianas, con presencia de síntomas negativos graves. Los objetivos serían la mejora de la calidad de vida y la consecución de cierto grado de independencia.

\subsubsection{Bases neurobiológicas}

Se han relacionado alteraciones en los sistemas cerebrales de neurotransmisión con la sintomatología psicótica en la esquizofrenia, destacando las teorías dopaminérgica, serotoninérgica o glutamatérgica, entre otras. La primera de ellas, aunque insuficiente, sería la más aceptada de todas (Saiz, Vega y Sánchez, 2010), además de por su importancia, por la implicación que tiene la dopamina en las adicciones a sustancias, realidad inseparable de la esquizofrenia, como se verá más adelante.

Por un lado, este neurotransmisor afecta a cuatro vías dopaminérgicas principales. Su hiperfunción en la vía mesolímbica se relaciona con la aparición de síntomas positivos, mientras que una hipofunción del mismo en la vía mesocortical lo hace con los síntomas negativos. Además, de manera indirecta, la medicación antipsicótica provoca efectos secundarios adversos en tres de estas vías, ya que esta tiene como fin bloquear los receptores dopaminérgicos D2 para disminuir los síntomas positivos. De esta forma, empeoraría la sintomatología negativa asociada a la vía mesocortical. En la vía nigroestriada, relacionada con el control de movimientos, se provocarían alteraciones motoras propias de la enfermedad de Parkinson. Y en la vía tuberoinfundibular, reguladora de la inhibición en la secreción de prolactina al torrente sanguíneo, se podrían producir, entre otras, galactorreas (secreciones anormales de leche) y disfunciones sexuales.

Por otro lado, se sabe que las sustancias psicoactivas tienen la capacidad de alterar los procesos de neurotransmisión en el sistema dopaminérgico mesocorticolímbico (Corominas, Roncero, Bruguera y Casas, 2007). El consumo agudo de drogas aumentaría la presencia de dopamina extracelular, mientras que su consumo de manera crónica la disminuiría en las vías mesolímbica y mesocortical.

\subsubsection{Tratamiento}

La esquizofrenia presenta una complejidad sintomatológica, unida a disfunciones en los planos funcional y social, que hace que para su tratamiento se deba recurrir a un modelo interdisciplinar que aúne la farmacología con medidas psicológicas, sociales, educativas, e incluso legales (Molina, 2013).

\section{a) Tratamiento con antipsicóticos}

Es muy común en esta enfermedad el incumplimiento terapéutico; algunas de las causas principales son la falta de conciencia de enfermedad (insight), el abuso de alcohol y drogas, la falta 
de apoyo familiar y social y los efectos secundarios de algunos antipsicóticos. En cuanto a estos últimos existen dos categorías con distintos efectos en el paciente (Carrasco y Maza, 2010).

Por un lado, se encuentran los llamados antipsicóticos típicos, como la clorpromazina o el haloperidol, que mejorarían los síntomas positivos como las alucinaciones o los delirios, pero que empeorarían los negativos. Además, producirían efectos secundarios adversos como los denominados síndromes extrapiramidales (relacionados con disfunciones motoras), aumento de peso, impotencia, taquicardias o diversos problemas en la vista.

Por el otro, se encuentran los antipsicóticos atípicos, de más reciente incorporación, como la clozapina o la risperidona, que mejorarían, además de los síntomas positivos, los negativos, y reduciría la aparición de síndromes extrapiramidales.

Además del tipo de fármaco usado, existe la posibilidad de que este sea administrado en forma de preparaciones de larga duración (antipsicóticos de depósito), donde la sustancia activa sería liberada progresivamente, con lo que únicamente se precisaría de una inyección cada 15 o 20 días. Esta opción plantea la ventaja de tener un mayor control sobre el cumplimiento terapéutico del paciente, y además, este podría vivir integrado en la sociedad y alejado del hospital psiquiátrico.

\section{b) Supuestos legales de tratamiento}

Desde el punto de vista legal, en muchos países existen ya legislaciones que regulan aquellos casos en los que se debe tratar a enfermos mentales en contra de su voluntad (Carrasco y Maza, 2010). Normalmente se refieren todas ellas a casos de internamiento, aunque también se expondrá aquí el tratamiento ambulatorio involuntario.

Según Carrasco y Maza (2010), los internamientos pueden ser voluntarios o involuntarios. En este último caso se necesita autorización judicial, previa solicitud de la propia familia, del representante legal del enfermo o del Ministerio Fiscal. Dichos internamientos son regulados tanto por la legislación civil como por la penal.

Por un lado, el artículo 763 de la Ley de Enjuiciamiento Civil prevé el internamiento por motivos médicos. Por otro lado, un proceso penal puede dar lugar a distintas situaciones en las que se entre a valorar o directamente se requiera de un internamiento. Estas son:

- Como consecuencia de la imposición de una medida de seguridad, tras la comisión de un delito y apreciarse inimputabilidad o semiimputabilidad en el autor de los hechos. Este aspecto se desarrollará más adelante en su correspondiente apartado.

- Durante la fase de instrucción o tras cometerse un delito. En este caso, antes de que sea emitida una sentencia, si se aprecian en el procesado indicios de trastorno mental, el juez puede decretar un internamiento según lo dispuesto en el artículo 381 de la Ley de Enjuiciamiento Criminal.

- Durante la fase de ejecución, cuando el penado presenta un trastorno mental sobrevenido, de acuerdo con el artículo 383 de la Ley de Enjuiciamiento Criminal.

- Tras pronunciarse sentencia firme condenatoria. Si en este caso se aprecia en el condenado un trastorno mental sobrevenido que le impide conocer el sentido de la pena, la ejecución de esta última se suspenderá. El juez garantizará que el enfermo reciba tratamiento médico adecuado en régimen de internamiento, si fuera necesario (art. $60 \mathrm{CP}$ ). 
- En cuanto al tratamiento ambulatorio involuntario, este ha ido desarrollándose en estos últimos años como solución a los llamados casos de «puerta giratoria» en los que se producen ingresos involuntarios con una alta frecuencia, corta duración y gran tasa de abandono de la medicación tras el alta (Carrasco y Maza, 2010). Esta posibilidad también difiere en sus vertientes penal y civil.

En el ámbito penal, esta modalidad de tratamiento sería una medida de seguridad no privativa de libertad, solo aplicable tras la comisión de un delito y la apreciación de inimputabilidad en el encausado. Hasta la reforma del Código Penal mediante la Ley Orgánica 5/2010 de 22 de junio, se contemplaban dos supuestos de tratamiento recogidos en el artículo 96.3.11를 y $96.3 .12^{a}$ :

La sumisión a tratamiento externo en centros médicos o establecimientos de carácter sociosanitario.

El sometimiento a programas de tipo formativo, cultural, educativo, profesional, de educación sexual y otros similares.

Tras la mencionada reforma, se suprimieron estos dos apartados, y la posibilidad del tratamiento ambulatorio forzoso se contempló como una de las medidas dentro de la libertad vigilada, recogida en el artículo 106.1.k):

La obligación de seguir tratamiento médico externo, o de someterse a un control médico periódico.

En su vertiente civil, esta medida iría destinada en especial a enfermos mentales graves, con falta de conciencia de su enfermedad, abandono del tratamiento y numerosos ingresos hospitalarios. A día de hoy, no existe una regulación específica en la legislación civil española, y tampoco existe consenso entre los profesionales de la salud sobre la necesidad de dicha especificidad legal, por ser entendida esta como una excesiva judicialización del tratamiento psiquiátrico (Carrasco y Maza, 2010). Sin embargo, hay juzgados que lo solicitan, llegando, incluso, a involucrar a la policía municipal para llevar al enfermo al ambulatorio con el fin de que le sea administrada su medicación (Gómez y Gómez, 2009). Sobre este punto se insiste más adelante en la entrevista con el magistrado Echarri Casi.

\subsubsection{Esquizofrenia dual}

La patología dual se puede definir como la coexistencia de dos enfermedades en el mismo sujeto. En el caso concreto de la esquizofrenia, la tasa de coexistencia (comorbilidad) entre esta y el abuso de sustancias oscila entre el 25 y el $58 \%$ (Vicente, Díaz y Ochoa, 2001), de ahí la importancia de su estudio.

En comparación con sujetos que solo tienen esquizofrenia, los pacientes duales presentan una serie de diferencias en cuanto a sintomatología psicótica, como bajos niveles de síntomas negativos y elevados de síntomas positivos (Tálamo et al., 2006) y depresivos (Potvin, Sepehry y Stip, 2007) y mejor funcionamiento cognitivo (Potvin et al, 2005). Sin embargo, la evolución de estos pacientes es habitualmente peor que aquellos que no consumen sustancias (Xie, McHugo, Helmstetter y Drake, 2005). Esto último se suele traducir en un aumento 
de intentos de suicidio (Potvin et al., 2005) o en problemas más frecuentes de violencia, delitos y vagabundeo (Potvin et al., 2005), entre otras consecuencias adversas.

En cuanto a algunas de las drogas que consumen estos pacientes y sus particularidades en esta patología, son las siguientes: la dependencia del tabaco es más habitual e intensa que en la población general (Martínez, Gurpegui, Díaz y de León, 2004); el uso de cocaína es más intermitente, posiblemente asociado a la presencia de síntomas positivos o negativos (Lysaker, Bell, Bioty y Zito, 1997), y el consumo de cannabis es también intermitente con una mejora del rendimiento neuropsicológico frente a los no consumidores (Jockers-Scherubl et al., 2007).

\section{a) Modelos comórbidos}

Dada la alta tasa de comorbilidad entre estos dos trastornos, han surgido múltiples teorías y modelos que intentan explicarla. Siguiendo la revisión de Mueser, Drake y Wallach (1998), algunos de los más importantes son:

- Modelos comunes. Señalan que la alta tasa de comorbilidad se debe a factores de riesgo o vulnerabilidades compartidas tanto por la esquizofrenia como por la adicción a sustancias, que pueden incrementar por sí mismos las posibilidades de sufrir ambas. Se han estudiado dos factores de riesgo en concreto: los genéticos y el padecimiento de un trastorno antisocial de la personalidad.

- Modelos de adicción secundaria. Estos modelos postulan que los pacientes con esquizofrenia desarrollan vulnerabilidades que los hacen ser más propensos al desarrollo de adicciones que el resto de la población. Existen tres teorías al respecto:

- En primer lugar, el modelo de automedicación afirma que los pacientes con trastornos mentales no comienzan a consumir sustancias al azar, sino que seleccionan aquellas que mejor alivien los síntomas causados por el trastorno mental.

- En segundo lugar, englobando al anterior, se encuentra el modelo de alivio de la disforia. Indica que los pacientes con enfermedades mentales son propensos a sufrir experiencias disfóricas, que, a su vez, les hace proclives al consumo de sustancias psicoactivas. Como los pacientes con esquizofrenia están particularmente expuestos a este tipo de experiencias, el alto grado de comorbilidad con el trastorno por uso de sustancias puede ser atribuido a los intentos por aliviarlas.

- Por último, se encontraría el modelo de múltiples factores de riesgo, mucho más general que los dos anteriores y capaz de explicar más situaciones comórbidas. Consiste en la integración de aquellos factores de riesgo comunes al trastorno por uso de sustancias y a la esquizofrenia que, a su vez, son consecuencia de esta última. Algunos de ellos son el aislamiento social, habilidades interpersonales y cognitivas pobres, fracaso escolar y profesional, pobreza, falta de responsabilidades adultas, falta de actividades diarias programadas, asociación con grupos desviados o vivir en vecindarios con una alta disponibilidad de drogas.

\section{b) Tratamiento}

A pesar de que la patología dual es ya una realidad conocida en los servicios de salud mental, aún hay muchos casos en los que el tratamiento de esta patología deja de lado el trastorno 
adictivo y se centra únicamente en el trastorno mental. Muchas veces esto se debe a la creencia de que el trastorno por uso de sustancias es un síntoma secundario de la enfermedad mental que cesará cuando esta última desaparezca (Negrete, 2010).

El tratamiento ideal es aquel que integra en uno solo los tratamientos de la drogodependencia y de la enfermedad mental, por parte del mismo personal y en un único centro (Horsfall, Cleary, Hunt y Walter, 2009). De esta manera, por ejemplo, al entrenamiento en habilidades sociales que se da en casos de psicosis se le añadirían elementos propios de las terapias por uso de sustancias, como maneras eficaces de responder a la incitación al consumo de drogas por otras personas (Jerrell y Ridgely, 1995; Ho et al., 1999). Por su parte, el trabajo motivacional propio de las terapias por consumo de sustancias debe adaptarse a las alteraciones motivacionales propias de la esquizofrenia, como la apatía, abulia o anhedonia (Negrete, 2010).

Por otra parte, es muy importante resaltar la correcta elección de la farmacoterapia en pacientes esquizofrénicos duales. Esto es así por la primacía que ostenta la administración de antipsicóticos en el tratamiento de la psicosis (Negrete, 2010). Como consecuencia de esto, algunas adicciones de estos pacientes podrían verse agravadas (Kosten, 1997; Krystal, D’Souza, Madonick y Petrakis, 1999; Green, 2005). Por ejemplo, se piensa que el paciente consumirá más para remediar la merma psíquica y la anhedonia que causan los antipsicóticos de acción bloqueadora más poderosa o persistente sobre los receptores dopaminérgicos D2. Este bloqueo produciría también la sensibilización de dichos receptores (Silvestri, Negrete, Seeman Shammi y Seeman, 2004), e incrementaría así el efecto de refuerzo positivo que ejerce la acción dopaminérgica de las drogas de abuso. En cuanto a los antipsicóticos atípicos, ya existe alguna evidencia empírica que recomienda su uso por encima de los anteriores, sobre todo en lo que se refiere a la clozapina (Noordsy y Green, 2003; Green, 2006).

\subsection{Violencia y enfermedad mental}

\subsubsection{Visión estigmatizada del enfermo mental}

Desde la perspectiva de la población general, se tiende a asociar el padecimiento de una enfermedad mental como la esquizofrenia con un elevado riesgo de peligrosidad, en gran parte gracias a los medios de comunicación. Por un lado, favorece esta visión la enorme atención mediática puesta en aquellos casos puntuales en los que enfermos mentales cometen delitos graves. Por otro lado, lo hace una lista de series, películas y libros donde se presenta a estas personas como delincuentes sin escrúpulos y asesinos en serie, formándose así una imagen de criminales cuyos actos son aleatorios, carentes de sentido y totalmente impredecibles (Esbec y Echeburúa, 2016; Stuart 2003). Todo ello provoca que en la opinión pública, ante hechos de extrema violencia, se acabe usando la enfermedad mental como justificante de los mismos, simplificando en exceso la relación que pudiera haber entre ambos y sin atender a otros factores (Arbach y Pueyo, 2007).

Diversos estudios han tratado de profundizar en este tema. De manera general, la investigación llevada a cabo en Alemania por Angermeyer y Matschinger (1995) mostró cómo la gente tiende a distanciarse del enfermo mental tras sucesos violentos y mediáticos, en este caso el intento de asesinato de dos importantes políticos de aquel país en 1990 por parte de dos personas que padecían esquizofrenia. Los niveles de distanciamiento social aumentaron 
marcadamente tras estos acontecimientos y, a pesar de que disminuyeron en los años consecutivos, siguieron sin volver a los niveles previos a 1990.

De forma más específica, se sabe también que la población suele atribuir distintos niveles de peligrosidad en función de la concreta enfermedad mental. Esto es lo que se desprende de un estudio llevado a cabo en Estados Unidos por Pescosolido, Monahan, Link, Stueve y Kikuzawa (1999), en el que se encuestó a casi un millar y medio de personas acerca de su percepción del riesgo de violencia en diversos trastornos. Los resultados sobreestimaron dicho riesgo para todos ellos, aunque acertaron en la jerarquización de los mismos. Para los drogodependientes se estimó un peligro del 87,3\% de cometer actos violentos sobre otras personas, para la esquizofrenia del 60,9\% y para la depresión mayor del 33,3\%.

Esta estigmatización y presunción de violencia pueden llevar al acoso y a otras formas de victimización del enfermo mental (Campbell, 1994), incluso dentro del propio núcleo familiar. En una investigación sobre dicha victimización en estos pacientes, se halló que el $63 \%$ de los que tenían una relación de pareja había sufrido alguna forma de agresión física en el último año por parte de sus compañeros sentimentales, y una cuarta parte de estos incidentes estaban relacionados con puñetazos, estrangulamientos y amenazas con armas. Lo mismo ocurría con el $46 \%$ de aquellos pacientes que convivían con miembros de su familia, de los cuales el $39 \%$ afirmaba haber sufrido violencia seria. Además, muchas personas que padecen enfermedades mentales graves viven en zonas peligrosas y empobrecidas donde tienen una mayor probabilidad de sufrir situaciones de violencia. En el estudio de Hiday, Swartz, Swanson, Borum y Wagner (1999) se observó que el 8,2\% de los enfermos mentales graves fueron víctimas de delitos en un periodo de cuatro meses, tasa que superaba a la anual entre la población general. Es muy importante tener estos datos presentes, ya que una historia de victimización y acoso hace a este tipo de pacientes más propensos a cometer actos violentos en el futuro (Hiday 1995).

Desde la perspectiva científica, existen posturas que difieren acerca de la peligrosidad de estos sujetos. Por un lado muchos investigadores de las ciencias sociales, psicólogos y criminólogos sostienen que la asociación entre enfermedad mental y violencia es una creencia falsa y prejuiciosa que agrava la estigmatización de los enfermos mentales como personas violentas. Para los defensores de esta idea, estos pacientes no mostrarían un comportamiento violento con más frecuencia que la población general (Morera, Hueso y Martínez, 2001; Arbach y Pueyo, 2007). Por otro lado, se encuentran aquellos profesionales de la salud que afirman que existe violencia frecuente en un limitado número de enfermos mentales, a la vista de su experiencia laboral (Wessely, 1997). Esta afirmación estaría respaldada por numerosos estudios epidemiológicos a gran escala llevados a cabo desde los años 80 del siglo xx que habrían encontrado un índice de prevalencia más elevado de violencia en pacientes psiquiátricos que en la población general, según Wessely.

Como ejemplo concreto y respaldo a esta postura, la mitad de los psiquiatras que trabajan en emergencias y en cuidados agudos en Canadá (donde el nivel de violencia global es más bajo que en el de la mayoría de países) afirman haber sido atacados por sus pacientes al menos una vez (Bourget, el-Guebaly y Atkinson, 2002). Sin embargo, esta experiencia clínica no es representativa del comportamiento de la mayoría de enfermos mentales, según Stuart (2003), ya que en este país se sigue un criterio de peligrosidad a la hora de ingresar a pacientes de esta naturaleza en cuidados agudos, por lo que los enfermos mentales más violentos estarían sobrerrepresentados. A pesar de ello, resulta lógico pensar que la opinión de 
muchos de los profesionales que atienden a estos pacientes sea la de que son más violentos, ya que ellos suelen ser víctimas frecuentes (Arbach y Pueyo, 2007).

\subsubsection{Violencia y esquizofrenia}

La agresividad se va conformando desde nuestro nacimiento como una respuesta adaptativa que nos ayude a superar amenazas externas, ya sean reales o imaginarias, y cuyos mecanismos regulativos van más allá de los simples impulsos y emociones, y el más importante de ellos es la intencionalidad de provocar un daño con una finalidad específica. Sin embargo, trastornos mentales como la esquizofrenia provocan una alteración en la percepción del entorno, y pueden hacer que todo sea visto como una amenaza, llevando a reacciones desproporcionadas y violentas (Arbach y Pueyo, 2007; Niechoff, 1999).

Una de las cuestiones más importantes a la hora de abordar este tema se centra en si los síntomas psicopatológicos son los principales causantes de la violencia o lo son también otros factores de riesgo comunes al comportamiento agresivo. Ninguna variable por sí misma puede explicar este tipo de conductas en los pacientes esquizofrénicos. Cada persona es un cúmulo de síntomas e historias vitales particulares que interacciona con un entorno social concreto. En la población general, algunos de los predictores de violencia más comunes son la juventud, el sexo masculino, un estatus socioeconómico bajo y la adicción a sustancias (Swanson, Swartz y Van Dorn, 2006).

En general, los esquizofrénicos no son más violentos que el resto de la población, siempre que estén controlados farmacológicamente, que no hayan sido dados de alta recientemente, que tengan una buena adherencia al tratamiento y que no consuman drogas (Arbach y Pueyo, 2007; Echeburúa y Loinaz, 2011; Esbec, 2005). Sin embargo, un importante porcentaje no recibe tratamiento adecuado, abandona la medicación, la toma de forma irregular o consume sustancias psicoactivas (Esbec y Echeburúa, 2016). A pesar de ello, es más probable que se hagan daño a sí mismos. El 10\% acaban suicidándose, porcentaje que se cuadruplica si existe abandono de medicación (Arseneault, Moffit, Caspi, Taylor y Silva, 2000).

La violencia, en caso de llegar a producirse, lo hace en entornos endonucleares y sin historia previa (sin conflictos anteriores con la víctima). Según la revisión llevada a cabo por Joyal, Putkonen, Paavola y Tiihonen (2004), entre el $50 \%$ y $60 \%$ de los agredidos son miembros de la familia, mientras que solo del $12 \%$ al $16 \%$ son desconocidos para el agresor, aunque este último porcentaje se eleva en casos de pacientes varones, adictos a las drogas y emancipados.

La mayoría de actos violentos cometidos por esquizofrénicos se relacionan con la sintomatología positiva, en especial con las alucinaciones y delirios. De esta manera, estos enfermos mentales pierden el contacto con la realidad, atribuyendo a los demás intenciones hostiles y dando credibilidad al producto de dichas alucinaciones. El subtipo de esquizofrenia más habitualmente relacionado con estos casos sería el paranoide. Los delirios más representativos serían los de celos, de persecución y mesiánicos (Echeburúa y Loinaz 2011).

Especial atención merece la incidencia de enfermedades mentales en la población carcelaria. Según el estudio efectuado por Fazel y Danesh (2002), acerca de veintiséis investigaciones que hicieron un seguimiento a 23.000 presos, estos tendrían entre dos y cuatro veces más probabilidades de padecer una enfermedad psicótica o una depresión mayor, y diez veces más posibilidades de desarrollar un trastorno antisocial de la personalidad. 


\subsubsection{Estudios sobre violencia y esquizofrenia}

A continuación, se expondrán los resultados de algunas de las numerosas investigaciones que tratan de cuantificar la relación entre la violencia y el padecimiento de esquizofrenia.

En el estudio llevado a cabo por Swanson et al. (2006) con una muestra de 1.410 personas con esquizofrenia, se analizó, por un lado, lo que se denominó violencia menor y, por otro, violencia seria. La primera sería aquella ejercida sin causar heridas ni usar armas, mientras que en la segunda sí que se producirían lesiones, se usarían armas letales, se amenazaría y se agrediría sexualmente. Los resultados fueron los siguientes:

- El $80,9 \%$ de los estudiados no mostró ninguno de los dos tipos de violencia antes mencionados.

- El 15,5\% de la muestra fue relacionado con la violencia menor. Se estableció una relación entre esta y la presencia de síntomas positivos (puntuación alta en la PANSS), abuso de sustancias, victimización reciente no violenta y numerosos años en tratamiento, entre otros factores.

- El 3,6\% presentó una violencia seria. Esta se asoció a problemas de conducta en la niñez, juventud, historial previo de detenciones y a síntomas positivos (puntuación por encima de la media en la PANSS), en especial, a la conducta alucinatoria, suspicacia/ perjuicio, hostilidad, excitación y grandiosidad. Además, se observó que los síntomas negativos reducían el riesgo de violencia seria, sobre todo la falta de espontaneidad y fluidez de la conversación, retracción social/apatía pasiva, embotamiento afectivo, pobre relación y dificultad de pensamiento abstracto.

Fazel, Gulati, Linsell, Geddes y Grann (2009) realizaron un metaanálisis comparando el riesgo de comisión de delitos violentos entre esquizofrénicos y la población general, poniendo especial atención en aquellos casos de comorbilidad entre el trastorno mental y la adicción a sustancias. Se tuvieron en cuenta los delitos de homicidio, agresiones, robo, incendio, agresión sexual, amenazas e intimidaciones. De las personas esquizofrénicas, entre el $12 \%$ y el $13 \%$ habían sido condenadas alguna vez por alguno de estos delitos frente al $5-8 \%$ del grupo de control. Sin embargo, al analizar por separado a esquizofrénicos con y sin trastornos de adicción a sustancias, se obtuvo que el 27,6\% de aquellos que eran adictos habían cometido un delito grave en algún momento, mientras que solo el $8,5 \%$ de los no adictos lo había hecho.

Por su parte, Tiihonen, Isohanni, Räsänen, Koiranen y Moring (1997) realizaron durante 26 años un seguimiento a 12.058 personas procedentes de las dos regiones más septentrionales de Finlandia. Durante ese periodo, el 2,2\% de los varones sin enfermedad mental cometieron al menos un delito violento, frente al $13,7 \%$ de los hombres con esquizofrenia. Además, el riesgo de cometer delitos entre los citados enfermos mentales, que además consumían alcohol, fue cuatro veces mayor que en los individuos que solo padecían esquizofrenia.

Que el riesgo de cometer delitos violentos por parte de pacientes psicóticos es más elevado que en la población general es un dato que se repite en varios estudios similares a los anteriormente expuestos, lo que podría llevar a la conclusión de que la violencia es un síntoma más de esta enfermedad. Sin embargo, como afirma Arbach y Pueyo (2007), el riesgo de violencia en esquizofrenia es moderado en comparación con el atribuido al abuso de sustan- 
cias y a los trastornos de personalidad, y comparable a otros factores tales como la juventud, el sexo masculino o el bajo nivel educativo.

\subsubsection{Variables predictoras}

Según la revisión llevada a cabo por Esbec y Echeburúa (2016), los factores que incrementan el riesgo de violencia en la esquizofrenia son:

a) Ausencia de tratamiento o incumplimiento del mismo.

b) Consumo de alcohol y drogas.

c) Historial de violencia y victimización.

d) Falta de conciencia de la enfermedad.

e) Síntomas positivos.

f) Aislamiento familiar y social.

g) Comorbilidad con un trastorno de la personalidad.

h) Tendencia a la introversión.

i) Sexo masculino y juventud.

j) Historia familiar de esquizofrenia.

k) Inicio de la enfermedad precoz.

l) Comienzo sin acontecimientos precipitantes.

De todos ellos, los autores destacan la ausencia e incumplimiento del tratamiento, el consumo de alcohol y otras drogas y la presencia de trastornos de la personalidad como los más significativos, debido a la especial incidencia que tienen en el desarrollo de esta enfermedad y en la aparición de conductas violentas.

\subsection{Valoración de la imputabilidad}

\subsubsection{Introducción a la noción de imputabilidad}

Antes de definir la imputabilidad, es necesaria una primera aproximación al concepto de delito. Según la teoría elaborada por el Derecho Penal, este se define como «la acción típicamente antijurídica y culpable, a la que la Ley señala una pena» (Carrasco y Maza, 2010). Es decir, el delito debe ser un acto previsto en la ley (típico) y contrario a la misma (antijurídico) ante el que el ordenamiento jurídico impone una pena (punible). Además de ello, debe ser una acción culpable, que pueda serle reprochada a su autor, no por el mero hecho de haberla cometido, sino tras efectuar una valoración de las condiciones subjetivas que le llevaron a ello. Y es aquí donde aparece la imputabilidad, entendida esta como el fundamento mismo de la culpabilidad, y sin el cual esta última no podría existir. La imputabilidad no sería más que la «capacidad de actuar culpablemente». A su vez, dicha capacidad es doble, ya que para que se tenga en cuenta, por un lado, el sujeto debe comprender la ilicitud del hecho y, por el otro, poder actuar libremente conforme a esa comprensión (Carrasco y Maza, 2010).

En el caso de enfermos mentales, dicha capacidad de entendimiento y libre elección puede verse afectada y llegar incluso a situaciones donde se vea completamente anulada. Por ello nuestro ordenamiento jurídico contempla atenuaciones e incluso exenciones completas de la pena según sea el caso. 
El Código Penal español, en su artículo 20, incluye tres causas de inimputabilidad que se ven frecuentemente relacionadas con dichos casos:

1. El que al tiempo de cometer la infracción penal, a causa de cualquier anomalía o alteración psíquica, no pueda comprender la ilicitud del hecho o actuar conforme a esa comprensión. El trastorno mental transitorio no eximirá de pena cuando hubiese sido provocado por el sujeto con el propósito de cometer el delito o hubiera previsto o debido prever su comisión.

2. El que al tiempo de cometer la infracción penal se halle en estado de intoxicación plena por el consumo de bebidas alcohólicas, drogas tóxicas, estupefacientes, sustancias psicotrópicas u otras que produzcan efectos análogos, siempre que no haya sido buscado con el propósito de cometerla o no se hubiese previsto o debido prever su comisión, o se halle bajo la influencia de un síndrome de abstinencia, a causa de su dependencia de tales sustancias, que le impida comprender la ilicitud del hecho o actuar conforme a esa comprensión.

3. - El que, por sufrir alteraciones en la percepción desde el nacimiento o desde la infancia, tenga alterada gravemente la conciencia de la realidad.

Por su parte, el artículo 21 contempla varias causas que atenúan la pena, de entre las cuales destacan dos de ellas por verse involucradas frecuentemente en estos casos:

1.- Las causas expresadas en el capítulo anterior, cuando no concurrieren todos los requisitos necesarios para eximir de responsabilidad en sus respectivos casos.

7. ${ }^{\text {a }}$ Cualquier otra circunstancia de análoga significación que las anteriores.

\subsubsection{Criterios jurisprudenciales}

Lo más importante a la hora de valorar la imputabilidad de una persona esquizofrénica, es establecer si hubo o no un nexo causal entre la sintomatología psicótica y los hechos delictivos.

Esto no siempre fue así. Antiguamente el criterio para acordar la inimputabilidad de un sujeto con esquizofrenia era el propio padecimiento de la misma, en virtud del principio in dubio pro reo, como queda recogido en las SSTS de 19 de diciembre de 1932, 22 de enero de 1964 o 29 de octubre de 1981, entre otras (Esbec y Echeburúa, 2016).

Más adelante, el Tribunal Supremo matizó esta postura, atendiendo al nexo causal existente entre el diagnóstico de esquizofrenia y los hechos delictivos cometidos por el sujeto. De esta forma este tribunal, además de valorar el efecto del trastorno mental en la responsabilidad penal (atendiendo al diagnóstico pericial de la existencia de una psicosis), también valora las consecuencias psicológicas específicas que dicho trastorno haya tenido en la conducta delictiva del acusado que se enjuicia. Esto se recoge en las SSTS de 3 de mayo de 1995 o 30 de noviembre de 1996, entre otras (Esbec y Echeburúa, 2016). Se trataría por tanto de determinar por un lado la existencia de una enfermedad mental en el sujeto, y por otro de precisar cómo afecta dicha enfermedad a las capacidades cognitivas y volitivas. Jurisprudencial y legalmente al primer paso se le denomina evaluación biológica y al segundo evaluación psicológica (Torre, 1999).

Recientemente, matizando aún más esta idea, la STS del 21 de febrero de 2013 señala los criterios comunes usados actualmente por la doctrina jurisprudencial en estos casos (Esbec y Echeburúa, 2016). Dichos criterios son: 
- La aplicación de la circunstancia eximente completa del art. 20.1 del Código Penal cuando el hecho se ha producido bajo los efectos de un brote esquizofrénico.

- El uso de la eximente incompleta del art. 21.1 si no se obró bajo ese brote, pero sí revelándose un comportamiento anómalo atribuible a esa enfermedad.

- La utilización de la atenuante analógica del art. 21.7 si el hecho delictivo es consecuencia del residuo patológico llamado defecto esquizofrénico (Esbec y Echeburúa, 2016).

Hay que tener en cuenta que en ocasiones las cadenas causales son demasiado largas y confusas, por lo que resulta difícil llegar a conocer el estado de las capacidades volitivas y cognitivas del sujeto en el momento del crimen. Esbec y Echeburúa (2016) señalan como esencial la toma en consideración no solo de la propia existencia de enfermedad mental sino también de otros factores, como aspectos psicobiográficos, antecedentes familiares, presencia de trastornos de la personalidad, análisis del apoyo familiar y social, antecedentes de conductas violentas, contexto social, cultural y económico, la conciencia de enfermedad o la adherencia al tratamiento. En cualquier caso insisten en la importancia de no caer en generalizaciones y de estudiar cada caso de manera individualizada.

\subsubsection{Simulación de psicosis}

En ocasiones, el paciente psicótico se vale de su experiencia previa con su propio trastorno para engañar a los peritos y obtener una sentencia favorable. En concreto, el paciente esquizofrénico crónico puede aprovecharse de diagnósticos previos ya acreditados con el fin de cometer delitos y sentirse de alguna manera impune (Esbec y Echeburúa, 2016). Según estos dos autores, algunos de los síntomas que diferencian una psicosis real de una simulada son:

- Referencia a un cuadro clínico alarmista y exagerado, con presencia de síntomas burdos, no habituales o contradictorios.

- Añadir un deterioro cognitivo pensando que «más es mejor».

- Relato monótono carente de componentes vivenciales y afectivos.

- No hacer referencia a conductas reactivas o evitativas propias de estos enfermos, como son los cambios de domicilio, quitar enchufes, levantar barricadas, pedir ayuda, viajar o tomar medicación.

- Falta de concordancia entre la simulación y el historial clínico real.

- Presencia de una actitud controladora y hostil, frente a la reticencia y desconfianza propias de la psicosis.

\subsubsection{Medidas de seguridad}

Carrasco y Maza (2010) exponen, para el caso concreto de los inimputables, la siguiente definición de medidas de seguridad:

Aquellas consecuencias jurídicas aplicables por el órgano jurisdiccional, en sustitución de una pena o conjuntamente con ella, a ciertos individuos (inimputables o semiimputables), autores de un hecho previsto como infracción criminal, que, por sus especiales características personales, fueren susceptibles de tratamiento terapéutico. 
Estos dos autores entienden que, pese a la reinserción y reeducación que sobrevuelan tanto las penas como las medidas de seguridad, la diferencia entre ambas radica en el tipo de prevención a la que responden. La primera de ellas lo hace ante una prevención tanto general como especial (reproche por la conducta y evitación de reiteración delictiva), mientras que la segunda solo se fundamenta en motivos de prevención especial, con el objetivo de neutralizar futuros actos delictivos o peligrosos de la persona sobre la que se impone.

Es en la peligrosidad precisamente donde encuentran su fundamento las medidas de seguridad. Cuando no se puede apreciar en el sujeto culpabilidad alguna por el hecho cometido, este resulta inimputable, y, por tanto, deja de ser objeto de reproche por su conducta y no se le impone pena alguna. Sin embargo, desde el punto de vista social, se debe dar una solución que sustituya a las penas en estos casos y que sea capaz de inocuizar futuras conductas violentas por parte del inimputado. Nótese además que el concepto de culpabilidad no necesariamente es proporcional al de peligrosidad. Esta última puede ser muy alta o muy baja, independientemente de la gravedad del delito cometido. A juicio de Carrasco y Maza (2010), la definición más acertada de peligrosidad sería una «...elevada probabilidad de delinquir en el futuro».

Es necesario apuntar que dicha peligrosidad, para ser tenida en cuenta, no debe ser transitoria, sino que debe presentarse de manera constante, lo que se denomina como estado peligroso, siendo tarea del juez su valoración, con el auxilio de la ciencia. Es destacable, con respecto a este último concepto, el paralelismo efectuado por Carrasco y Maza (2010). Afirman que si, por un lado, el delito, la culpabilidad y la imposición de una pena deben valorarse retroactivamente, el estado peligroso, la peligrosidad y la aplicación de una medida de seguridad lo hacen mirando hacia el futuro. A continuación se exponen aspectos legales de las medidas de seguridad:

\section{a) Principios rectores}

- Legalidad: en el caso de las medidas de seguridad, este principio deviene en una triple exigencia. Dichas medidas deben estar recogidas en las leyes, así como los supuestos de aplicación de cada una de ellas y su adaptación al caso concreto. Sin embargo, al contrario que en la ejecución de las penas, las medidas de seguridad pueden adaptarse flexiblemente a las necesidades de cada individuo a la vista de su evolución.

- Jurisdiccionalidad: estas medidas solo podrán ser impuestas por un órgano jurisdiccional (jueces o tribunales), aunque ello no impida que dichos órganos se vean auxiliados por otras figuras como facultativos y profesionales (arts. 98 y $105 \mathrm{CP}$ ), servicios de la administración (art. 105.2 CP), servicios de asistencia social competentes (art. 106 CP) o, incluso, familiares a los que se les asigna la custodia del sujeto (arts. $96.24^{\mathrm{a}}$ y 105.1 b) CP). Asimismo, el juez de vigilancia penitenciaria tendrá también un papel en algunos de los momentos de cumplimiento de las medidas que la ley prevé, como la propuesta de mantenimiento, cese, sustitución o suspensión de las mismas (art. $98 \mathrm{CP}$ ), la participación en la custodia familiar (arts. $96.34^{\mathrm{a}}$ y 105.1 b) CP) o los informes sobre cumplimiento de algunas de las medidas (art. $105 \mathrm{CP}$ ).

- Proporcionalidad: en opinión de Carrasco y Maza (2010), la aplicación de este principio a día de hoy es errónea, ya que se busca la proporción entre la medida de seguridad 
y el hecho cometido, como se aprecia en los artículos 101, 102 y 103 del Código Penal, en los que se especifica que la duración de las medidas de seguridad para aquellos inimputables de los artículos 20.1, 20.2 y 20.3 del Código Penal no podrá exceder del tiempo que habría durado la pena en caso de haber sido condenados. Lo correcto sería, por tanto, la adecuación de la medida de seguridad a la peligrosidad del sujeto, sin que pudiera existir límite temporal mientras dicha peligrosidad no desapareciera.

- Finalidad terapéutica: no cabe duda de la finalidad asegurativa (de prevención especial) que poseen las medidas de seguridad. En principio, el fin terapéutico no se opone a esta, sino que son compatibles entre sí. Según Carrasco y Maza (2010), actualmente puede producirse un abandono de esta última finalidad, por un lado, por los insuficientes resultados terapéuticos obtenidos hasta el momento y, por otro, por la ya explicada adecuación de las medidas de seguridad a la entidad del delito cometido más que a la peligrosidad del sujeto. A pesar de ello, en el Código Penal esta pretensión curativa es observable en los artículos 97, 99, 101, 102, 103 y 105, al hacer alusión a tratamientos en centros hospitalarios, de deshabituación o educativos, o al contemplar la posibilidad de suspender la ejecución de una pena consecutiva a una medida, si se pudieran poner en peligro los logros obtenidos en la segunda de ellas, por ejemplo.

- Obligatoriedad: este principio no exige la obligada aplicación de medidas de seguridad a los inimputables, como se podría pensar, sino la obligatoriedad de las mismas una vez que son impuestas por el juez. Así lo indican las expresiones recogidas en el Código Penal como «podrá aplicar, si fuere necesaria»; «aplicará, si fuere necesaria»; «podrá imponer»; «podrá imponer razonadamente» 0 «podrá decretar razonadamente» en los artículos 101.1, 103.1, 102.1, 104, 105 y 107. Esto contrasta, sin embargo, con la redacción del artículo 95.1 que recoge esta expresión: «Las medidas de seguridad se aplicarán... », contrarrestada por los artículos anteriores. Por tanto, se podría no imponer medida de seguridad alguna si no se aprecia en el sujeto peligrosidad (Carrasco y Maza, 2010).

\section{b) Supuestos legales}

Según se establece en el Código Penal (art. 95), hay tres requisitos para la aplicación de las medidas de seguridad:

- Que el sujeto sea declarado inimputable conforme a los artículos 20.1, 20.2 y 20.3 o le sea de aplicación la eximente incompleta del artículo 21.1 en relación con los anteriores artículos (art. 95.1 CP).

- «Que el sujeto haya cometido un hecho previsto como delito» (art. $95.11^{\text {a }} \mathrm{CP}$ ).

- «Que del hecho y de las circunstancias personales del sujeto pueda deducirse un pronóstico de comportamiento futuro que revele la probabilidad de comisión de nuevos delitos» (art. 95.1 2 ${ }^{\underline{a}}$ ).

Además, para que la medida de internamiento pueda decretarse, es necesario que concurran dos requisitos más. Dicho internamiento debe ser realmente necesario y la pena prevista para los hechos cometidos debe suponer privación de libertad. 


\section{c) Medidas}

Las medidas de seguridad existentes se recogen en el artículo 96 del Código Penal:

1. Las medidas de seguridad que se pueden imponer con arreglo a este Código son privativas y no privativas de libertad.

2. Son medidas privativas de libertad:

1. ${ }^{a}$ El internamiento en centro psiquiátrico.

2. ${ }^{a}$ El internamiento en centro de deshabituación.

3. ${ }^{a}$ El internamiento en centro educativo especial.

3. Son medidas no privativas de libertad:

1. - La inhabilitación profesional.

2. ${ }^{\text {a }}$ La expulsión del territorio nacional de extranjeros no residentes legalmente en España.

3. ${ }^{a}$ La libertad vigilada.

4. ${ }^{-}$La custodia familiar.

5. ${ }^{a}$ La privación del derecho a conducir vehículos a motor y ciclomotores.

6. ${ }^{\text {a }}$ La privación del derecho a la tenencia y porte de armas.

Como se puede observar, la medida de internamiento se divide en tres categorías distintas. Esto se establece en función del apartado del artículo 20 que haya dado lugar a la inimputabilidad, y así, el Código Penal establece en sus artículos 101, 102 y 103:

Artículo 101

1. Al sujeto que sea declarado exento de responsabilidad criminal conforme al número $1 . .9$ del artículo 20 , se le podrá aplicar, si fuere necesaria, la medida de internamiento para tratamiento médico o educación especial en un establecimiento adecuado al tipo de anomalía o alteración psíquica que se aprecie, o cualquier otra de las medidas previstas en el apartado 3 del artículo $96 \ldots$

Artículo 102

1. A los exentos de responsabilidad penal conforme al número $2 . .^{\circ}$ del artículo 20 se les aplicará, si fuere necesaria, la medida de internamiento en centro de deshabituación público, o privado debidamente acreditado u homologado, o cualquiera otra de las medidas previstas en el apartado 3 del artículo 96...

Artículo 103

1. A los que fueren declarados exentos de responsabilidad conforme al número 3.0 del artículo 20, se les podrá aplicar, si fuere necesaria, la medida de internamiento en un centro educativo especial o cualquier otra de las medidas previstas en el apartado tercero del artículo 96...

A estos tres supuestos se le suma el del caso de los semiimputables del artículo 21.1 en relación con el artículo $20.1,20.2$ y 20.3 que se recoge en el artículo 104: 


\section{Artículo 104}

1. En los supuestos de eximente incompleta en relación con los números $1 .^{\circ}, 2 . .9$ y $3 . \circ$ del artículo 20, el juez o tribunal podrá imponer, además de la pena correspondiente, las medidas previstas en los artículos 101, 102 y $103 \ldots$

\section{Hipótesis y objetivos}

\subsection{Hipótesis}

1. Los factores de riesgo asociados a un aumento de la violencia en esquizofrenia contribuyen a la comisión de delitos.

2. En la doctrina jurisprudencial actual, el diagnóstico de esquizofrenia, por sí mismo, no implica la inimputabilidad del acusado.

3. La obligación de seguir tratamiento ambulatorio involuntario, en casos de delitos cometidos por esquizofrénicos, no es una medida de seguridad que se aplique en la práctica de los tribunales penales españoles.

\subsection{Objetivos}

1. Comprobar si los factores que aumentan el riesgo de violencia en esquizofrenia están representados en la jurisprudencia.

2. Comprobar si el paciente diagnosticado de esquizofrenia no siempre delinque como consecuencia de su enfermedad.

3. Revisar el tratamiento jurisprudencial que se hace de la inimputabilidad en casos de esquizofrenia.

4. Revisar las medidas de seguridad decretadas en casos de esquizofrenia.

\section{Metodología}

Con el fin de alcanzar los objetivos fijados, se lleva a cabo una revisión de sentencias del Tribunal Supremo de los últimos 10 años relacionadas con la esquizofrenia. Se realiza, además, una entrevista al magistrado de la Audiencia Nacional Fermín Javier Echarri Casi, con el fin de completar información y aportar el punto de vista de un profesional de la judicatura.

En una primera fase, se recurre al buscador de jurisprudencia del Centro de Documentación Judicial del Consejo General del Poder Judicial (CENDOJ). Se descartan aquellas sentencias ajenas al objeto de esta investigación, siguiendo los criterios de exclusión expuestos más adelante.

En una segunda fase, se recurre a la búsqueda, en la misma base de datos, de las sentencias de primera y segunda instancia que motivaron los recursos que dieron lugar a las sentencias de casación seleccionadas, con el fin de completar aquella información que pudiera faltar en ellas. 


\subsection{Criterios de selección}

Se analizan sentencias:

- Del Tribunal Supremo, más las sentencias correspondientes de instancias anteriores.

- De la jurisdicción penal.

- En las que aparezca la palabra clave: esquizofrenia.

- Aquellas en las que el acusado o alguno de ellos esté diagnosticado de esquizofrenia y resulte finalmente condenado.

- Desde el 01/01/2008 hasta el 01/01/2018.

Se excluyen, aun conteniendo la palabra clave, aquellas sentencias donde:

- El acusado presenta un trastorno psicótico distinto de la esquizofrenia, o un trastorno mental diferente.

- No se menciona la palabra esquizofrenia en relación con el acusado, sino al hacer referencia a otras sentencias o casos.

- La esquizofrenia es padecida por la víctima o por cualquier otra persona relacionada con la causa distinta del acusado.

- Los médicos forenses determinan que el acusado, en realidad, no padece esquizofrenia.

- La palabra esquizofrenia no se utiliza en ningún momento en términos de salud mental. Por ejemplo, se descartan sentencias donde aparecen expresiones como «esquizofrenia procesal» 0 «esquizofrenia gramatical».

- El acusado finalmente fue absuelto de los delitos que se le imputaban al no ser hallado culpable de los mismos.

\subsection{Metodología de búsqueda}

METODOLOGÍA DE LA BÚSQUEDA

Base de datos: CENDOJ

Palabra clave: esquizofrenia

Tipo de órgano: Tribunal Supremo Jurisdicción: penal

Tipo resolución: sentencia

Fecha resolución: 01/01/2008 a 01/05/2018

Sentencias de los Tribunales Superiores de Justicia $(n=5)$

Sentencias de las Audiencias Provinciales $(n=34)$ 


\subsection{Variables seleccionadas}

Se seleccionan las siguientes variables:

- Sexo.

- Delito.

- Circunstancia modificativa de la responsabilidad penal: en este caso únicamentese recogen la eximente completa del artículo 20.1 y los atenuantes de los artículos 21.1 y 21.2, por su relación con las enfermedades mentales y las drogas.

- Medida de seguridad/Prisión: se recoge la medida de seguridad adoptada o, en su caso, la prisión decretada.

- Víctima del entorno: se tienen en cuenta tanto familiares directos como personas con las que conviviera o hubiera convivido el acusado.

- Tipo de esquizofrenia: el tipo de esquizofrenia al que se haga referencia en la sentencia.

- Comorbilidades: aquí se recogen los casos de comorbilidad con adicción a sustancias, trastornos de la personalidad u otras.

- Diagnósticos previos: tanto de esquizofrenia como de otros trastornos comórbidos.

- Tratamiento: se especifica si el acusado se encontraba bajo tratamiento en el momento de comisión del delito.

- Afectación capacidades intelectivas y volitivas: si estas se encontraban completamente anuladas, afectadas de forma grave o leve o sin afectación.

- Nexo causal: se recoge si hubo relación entre el padecimiento de esquizofrenia y el delito.

\section{Resultados y discusión}

\subsection{Resultados}

Tras la revisión de las 73 sentencias relacionadas con los 34 casos escogidos, los resultados, ordenados en forma de tablas, se recogen en el apartado de anexos (tablas 4-8). Se expone a continuación el recuento de los datos obtenidos en función de la variable estudiada y de los objetivos de este trabajo. Aparece también la entrevista realizada al magistrado de la Audiencia Nacional Fermín Javier Echarri Casi.

\section{a) Factores de riesgo}

En primer lugar, de los 34 casos, en 26 de ellos el acusado padecía esquizofrenia paranoide, 2 de ellos residual, 1 de ellos hebefrénica, 1 indiferenciada y 1 desorganizada. Hay 3 casos en los que no se especifica el tipo de esquizofrenia padecida. En 12 de los casos se presentaba una comorbilidad con consumo de drogas (en el resto no se especifica), un trastorno de la personalidad en 4 de ellos y otro tipo de trastorno en otros 4 casos. En cuanto al diagnóstico de dichas enfermedades con anterioridad al delito, la esquizofrenia lo estaba en 27 de los 34 casos, el consumo de drogas en 10 de los 12, los trastornos de la personalidad en todos los casos y los otros trastornos también. 
Tabla 1. Enfermedades mentales y diagnóstico previo

\begin{tabular}{|c|c|c|c|}
\hline Enfermedad mental & Tipo & № & Diagnóstico previo \\
\hline Esquizofrenia & $\begin{array}{c}\text { Paranoide } \\
\text { Residual } \\
\text { Hebefrénica } \\
\text { Desorganizada } \\
\text { Indiferenciada } \\
\text { No especifica }\end{array}$ & $\begin{array}{c}26 \\
2 \\
1 \\
1 \\
1 \\
3\end{array}$ & $27 / 34$ \\
\hline Drogas & & 12 & $10 / 12$ \\
\hline $\begin{array}{l}\text { Trastorno de la } \\
\text { personalidad }\end{array}$ & $\begin{array}{c}\text { Límite } \\
\text { Esquizoide } \\
\text { Antisocial } \\
\text { No especifica }\end{array}$ & $\begin{array}{l}1 \\
1 \\
1 \\
1\end{array}$ & $4 / 4$ \\
\hline Otro trastorno & $\begin{array}{c}\text { Delirante } \\
\text { Adaptativo y disociativo } \\
\text { Esquizoafectivo } \\
\text { Depresión }\end{array}$ & $\begin{array}{l}1 \\
1 \\
1 \\
1\end{array}$ & $4 / 4$ \\
\hline
\end{tabular}

En 5 casos el sujeto se encontraba bajo tratamiento en el momento de cometer el delito, mientras que en 15 no lo estaba. En el resto de casos no se especifica. Además, 32 de los acusados eran varones, frente a 2 mujeres.

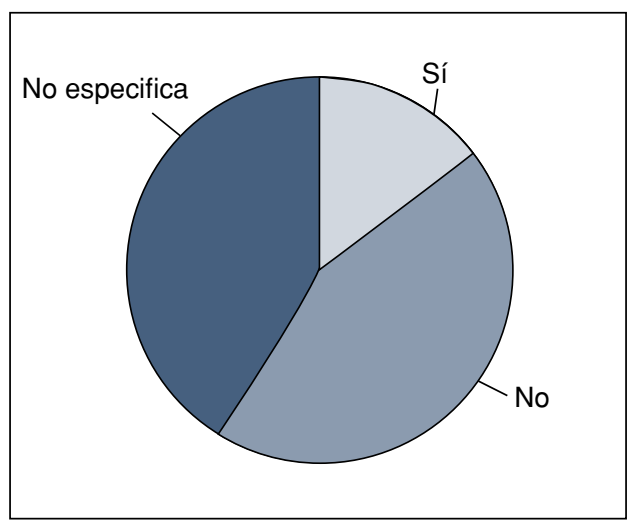

Figura 1. Presencia de tratamiento en el momento del delito.

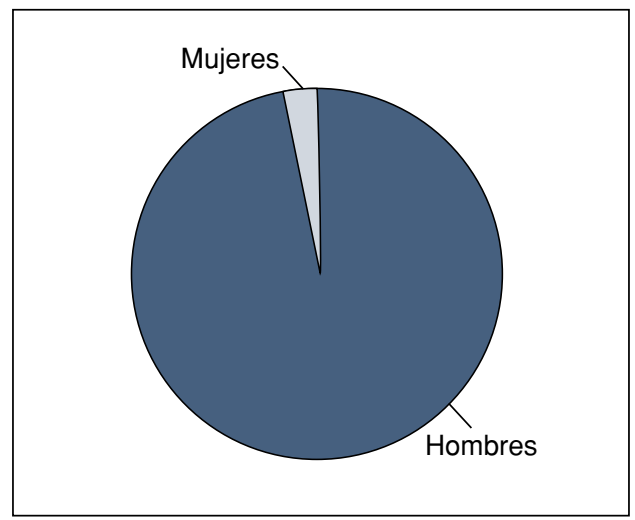

Figura 2. Datos obtenidos en función del sexo.

\section{b) Imputabilidad}

En segundo lugar, están los datos sobre la afectación de la enfermedad sobre las capacidades volitivas e intelectivas en el momento de cometer el delito. En 8 casos dichas capacidades se encontraban totalmente anuladas, en 8 estaban afectadas de forma grave, en 4 de manera leve y en 13 no lo estaban en ningún grado. Solamente en un caso no se especifica esta cuestión. De la revisión se desprende que en 20 de los casos hubo un nexo causal entre la esquizofrenia y el delito, frente a los 13 en los que dicha relación no existió. 


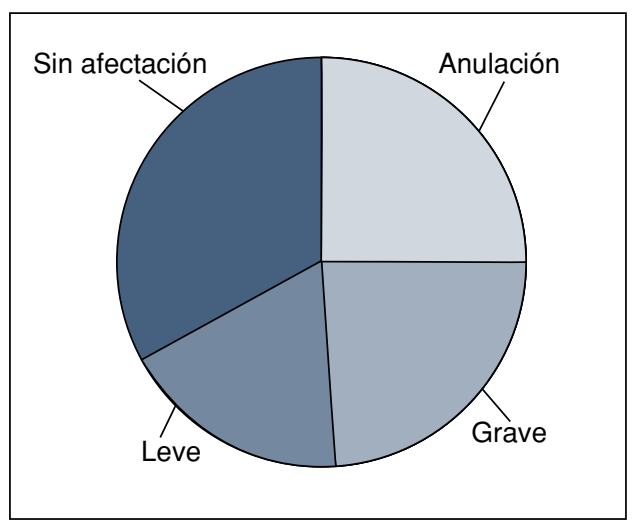

Figura 3. Afectación de las capacidades intelectivas y volitivas del sujeto.

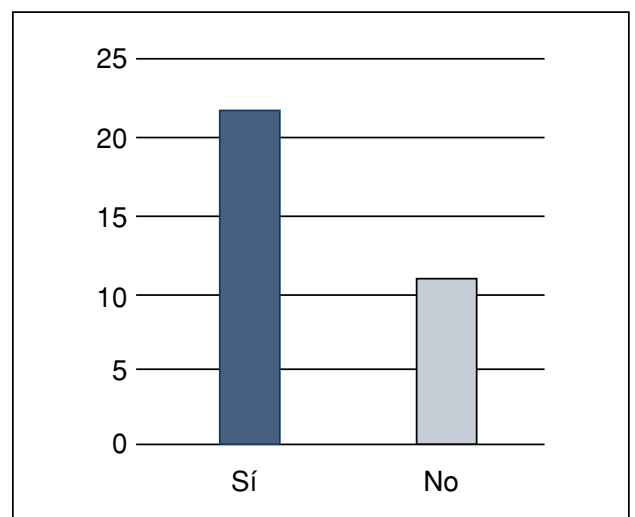

Figura 4. Nexo causal entre la esquizofrenia y el delito.

En cuanto a las circunstancias modificativas de la responsabilidad, la eximente completa del artículo 20.1 se aplicó nueve veces, la eximente incompleta del artículo 21.1 ocho veces, la atenuante analógica del 21.7 seis veces y la atenuante de drogadicción del 21.2 una vez. En 10 casos no se aplicó ninguna de las anteriores.

Figura 5. Circunstancias modificativas de la responsabilidad criminal.

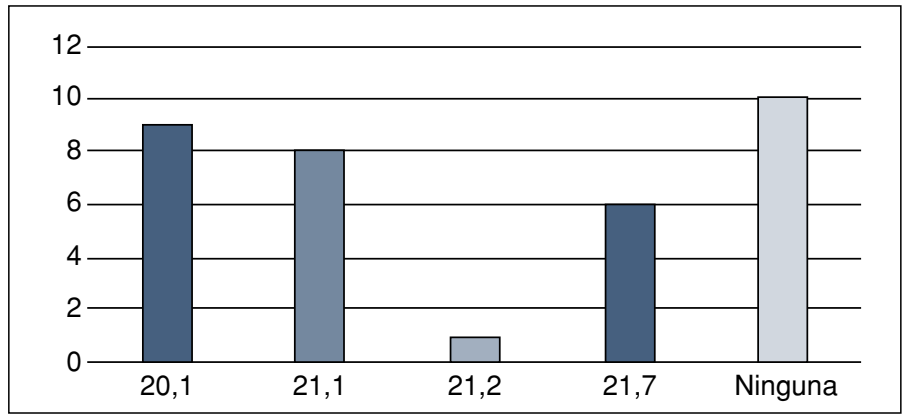

\section{c) Prisión y medidas de seguridad}

En tercer lugar, se decretó el ingreso en prisión en 23 de los casos, internamiento en centro psiquiátrico penitenciario en 5 ocasiones, 3 ingresos en centro psiquiátrico, 2 en centro adecuado y 1 en centro médico o tratamiento ambulatorio.

Figura 6. Prisión y medidas de seguridad.

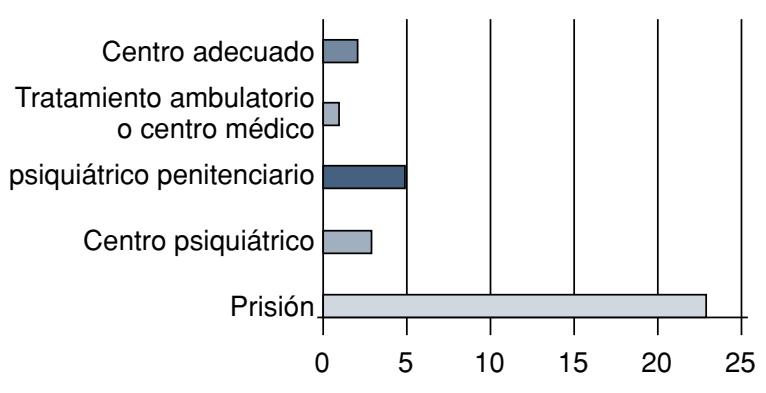




\section{d) Otros resultados}

De los delitos contra las personas, sin tener en cuenta el grado de ejecución, se cometieron 16 contra la vida (7 asesinatos y 9 homicidios), 6 de lesiones, 4 delitos contra la libertad e indemnidad sexual ( 2 agresiones sexuales y 2 abusos sexuales) y 3 contra la libertad (2 detenciones ilegales y 1 amenaza). Se cometieron, además, 5 delitos contra el patrimonio (4 de robo y 1 de estafa) y 2 de incendio. Por último, hubo 4 delitos contra la salud pública, 1 delito de falsedad documental, 1 de apropiación indebida, 1 de atentado a la autoridad, 1 de cohecho, 1 de abuso de funciones y 1 de revelación de secretos.

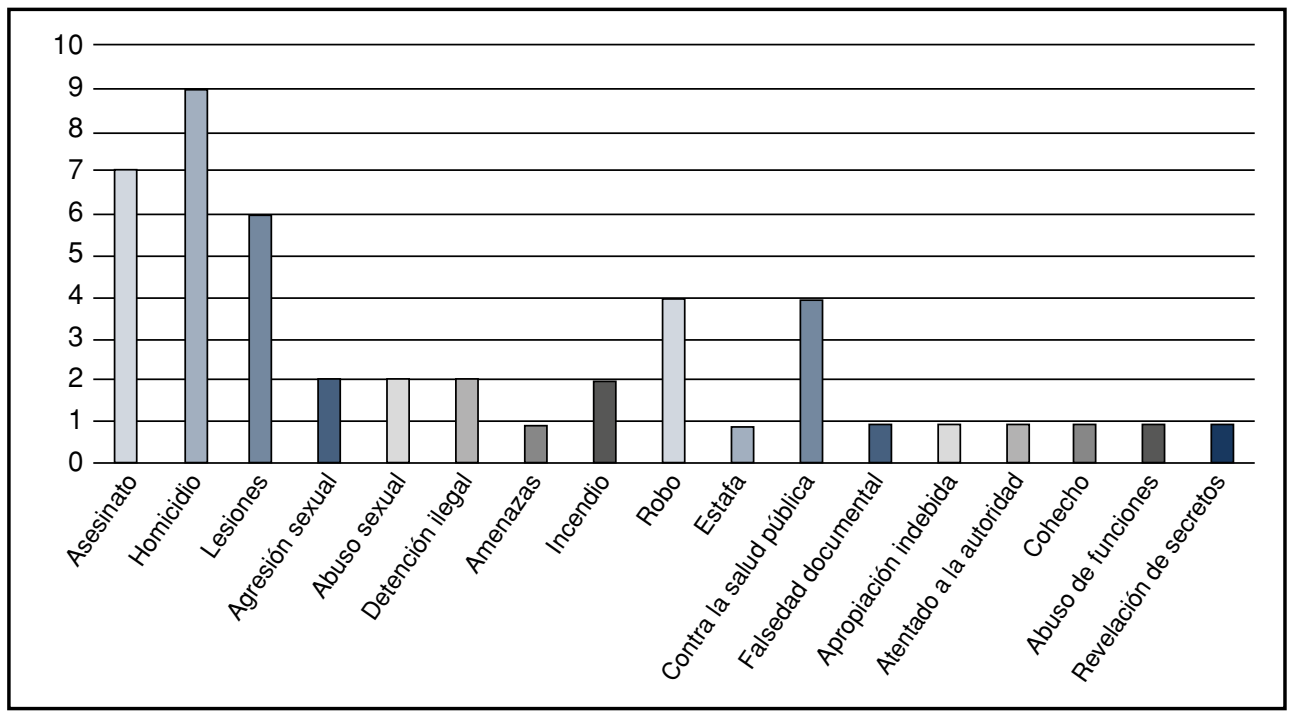

Figura 7. Delitos cometidos.

En 15 de los casos las víctimas eran del entorno (19 no lo eran).

Figura 8. Víctimas del

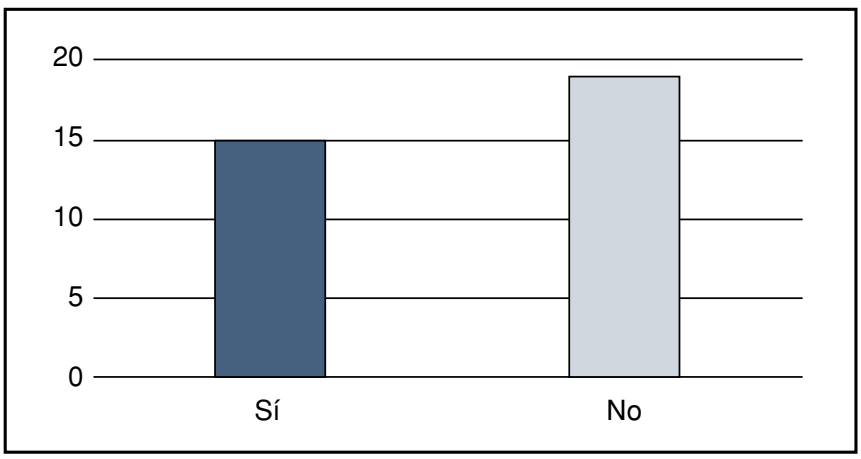

entorno del agresor.

\section{e) Entrevista con el magistrado Fermín Javier Echarri Casi}

A lo largo de la realización de este trabajo se me planteó la posibilidad de completar la información añadiendo el punto de vista de un profesional de la judicatura. Solicité una entrevista 
al Magistrado Echarri Casi, quien tuvo la amabilidad de recibirme en su despacho de la Audiencia Nacional y, con gran generosidad y paciencia, me fue orientando sobre los siguientes temas: los factores de riesgo en personas con esquizofrenia, los criterios jurisprudenciales en cuanto a imputabilidad establecidos por el Tribunal Supremo, el tratamiento ambulatorio involuntario como medida de seguridad no privativa de libertad y el diagnóstico de los enfermos mentales antes y después de la publicación del DSM-5.

En relación con los factores de riesgo, dicho magistrado considera que las personas con esquizofrenia sufren una gran victimización por su situación, viéndose abocadas a la marginación social y laboral. Esto se agrava aún más cuando han cometido un delito, haciéndose muy difícil la resocialización, ya que son personas que no cuentan con dotes sociales, intelectuales o laborales para rehacer su vida. Están, en definitiva, abocadas a depender de su familia.

Apunta a la falta de tratamiento y al consumo de drogas como los factores que más predisponen a la violencia en estos enfermos. Reconoce, además, que este último constituye un problema de vigilancia penitenciaria, al ser posible el acceso a la droga en el interior de las prisiones. Y se debe tener en cuenta, igualmente, la falta de personal especializado en psiquiatría forense (son más abundantes en otras ramas de la medicina) y de una infraestructura adecuada para el tratamiento de estos casos en el ámbito penal.

En cuanto al reflejo de dichas cuestiones en la jurisprudencia, señala que los jueces tienen en cuenta en sus sentencias aquellos factores que hacen a los acusados peligrosos. Por tanto, concurran o no los mencionados factores de riesgo, solamente aparecerán aquellos que hayan sido esenciales para la resolución de la causa, estando el resto de ellos ya reflejados en los informes periciales.

En lo tocante a los criterios jurisprudenciales del Tribunal Supremo, afirma que no siempre tiene por qué existir un nexo causal entre el padecimiento de esquizofrenia y el delito cometido. En ocasiones se producen altercados con familiares a raíz de discusiones sin que exista un brote psicótico. Por otra parte, señala que es muy común la aplicación de la atenuante analógica cuando no hay certeza acerca de la afectación de las capacidades del enfermo el día de los hechos, pero se vienen manifestando síntomas de la enfermedad desde ese momento. Por ello es tan importante el examen forense cercano a la fecha del delito. Si este se retrasa en el tiempo, será muy difícil poder aplicar la atenuante de eximente incompleta y mucho más la eximente completa. A pesar de ello, hay ocasiones en las que, si el médico forense acredita que se trata de un individuo con una enfermedad mental grave de largo recorrido y especialmente sintomática, se pueden llegar a aplicar dichas circunstancias modificativas, aun cuando el informe forense relativo al delito esté lejano en el tiempo, al igual que ocurre con los drogodependientes.

Este juez considera los criterios actuales establecidos por el Alto Tribunal como adecuados, ya que se centran en la afectación de las capacidades volitivas e intelectivas del sujeto, pudiendo discriminar aquellos casos sin nexo causal alguno. Teniendo siempre presente que dichos criterios deben irse modificando según avance la medicina, ya que esta debe estar por encima del derecho en estas cuestiones.

En cuanto al tema del tratamiento ambulatorio involuntario como medida de seguridad no privativa de libertad, en principio, contempla esta posibilidad como accesoria o complementaria a una medida de seguridad privativa de libertad. Al estar el sujeto interno, este se 
encuentra tutelado por el Estado bajo un régimen especial de sujeción, y por tanto sí se le puede obligar a recibir tratamiento. No ve factible, sin embargo, la posibilidad de esta medida en régimen de libertad. Si el sujeto se encuentra en libertad, no se puede ir en contra de su autonomía como paciente y administrarle un tratamiento por la fuerza.

Encuentra la redacción del artículo 106.1 k) del Código Penal (que establece la obligatoriedad de someterse a estos tratamientos estando el individuo en libertad vigilada) como un ejercicio de voluntarismo penal y de redacción taxativa, que en nada favorece estos casos. $A$ pesar de dicha obligatoriedad, piensa que no se puede obligar a nadie a tratarse por la fuerza. Argumenta, además, que el legislador penal no ha previsto la consecuencia de incumplir este precepto. Esta situación conllevaría un delito de quebrantamiento de medida, pero eso no resuelve el tema del tratamiento. Es más, afirma que no se podría imponer otra medida de seguridad más restrictiva o incluso privativa de libertad, ya que el juez estaría yendo en contra de la naturaleza de su propio fallo y, en cualquier caso, no ayudaría a la mejoría de la enfermedad mental. Como mucho, sostiene, se podría imponer prisión provisional en referencia al procedimiento por quebrantamiento de medida, donde sí que se le podría tratar por la fuerza. Sin embargo, esta opción en realidad no es viable, ya que no estaría en relación ni con la medida incumplida ni con el delito cometido, sino con el de quebrantamiento.

Considera que nunca se debió cambiar el artículo 76.3.11ª reformado por la LO 5/ 2010, en el que se recogía el tratamiento forzoso ambulatorio como una medida de seguridad autónoma y ajena al ámbito de la libertad vigilada. Este precepto no imponía obligatoriedad alguna, sino que dejaba, en última instancia, la decisión al propio paciente.

Dentro de esta cuestión, se abordaron también las experiencias piloto llevadas a cabo en algunos puntos de España ya mencionadas en este trabajo, donde la policía acompañaba al enfermo al ambulatorio para que el médico le administrara la medicación (Gómez y Gómez, 2009). Afirma que se trata de un tema delicado, al no estar correctamente legislado. Teniendo en cuenta, además, que la policía no suele prestarse a coaccionar al enfermo si no es por una orden judicial, y que por tanto su presencia serviría más bien como garantía de la seguridad del facultativo que como agente impositivo.

Por último, se abordó el asunto del diagnóstico de los subtipos esquizofrénicos en las sentencias revisadas, a pesar de que el DSM-5 los eliminó y fue publicado hace años. Este es un tema que compete más bien a los peritos que emiten el dictamen forense y, por tanto, su elaboración es ajena al tribunal. Sin embargo, es importante señalar que independientemente de los criterios utilizados, lo importante es si de este diagnóstico se puede extraer alguna consecuencia jurídica. A la vista de que se sigue usando la formulación del DSM-4, este magistrado afirma que cabría la posibilidad de que alguna de las partes incorporara un dictamen pericial distinto que intentara desacreditar al primero en base a lo obsoleto de su diagnóstico. Existiría el riesgo por otro lado de falta de objetividad, al ser una prueba aportada a instancia de parte.

\subsection{Discusión}

Las hipótesis y objetivos de este trabajo ponen el foco en los factores de riesgo, la imputabilidad y el tratamiento ambulatorio involuntario. A continuación se discutirán los resultados obtenidos para cada uno de estos puntos. 
En primer lugar, se aprecia la presencia de múltiples factores de riesgo asociados a la violencia en esquizofrenia en los 34 casos estudiados. El sexo masculino predomina en todos ellos, seguido de la esquizofrenia de tipo paranoide. La ausencia de tratamiento en el momento de los hechos y el consumo de drogas aparecen también en múltiples ocasiones. Hay que tener en cuenta que en bastantes casos no se especifica estas cuestiones.

Ocho de los sujetos que se encontraban sin tratar ( $n^{\circ} 1,9,17,20,24,25,27$ y 30) presentaron una afectación de sus capacidades volitivas e intelectivas que iban de la gravedad a la completa anulación, frente a los seis casos ( $n$-21, 26, 28, 29, 31 y 32) que no se vieron afectados (más uno levemente, el no 18). En la mayoría de los casos en los que no se especifica esta cuestión la afectación fue grave o plena. Por su parte, ninguno de los sujetos que se encontraban bajo tratamiento superó una leve afectación de estas capacidades. Esto podría llevar a pensar que, en muchos de los casos en los que no se recoge la presencia de tratamiento, en realidad, este no existía, aunque no se pueda saber con certeza. Además, siendo el incumplimiento terapéutico tan frecuente en este tipo de pacientes, sería adecuado que la jurisprudencia reflejara, en todos los casos, la presencia o ausencia de dicho tratamiento.

Tabla 2. Relación del tratamiento con la afectación de las capacidades

\begin{tabular}{|l|c|c|}
\hline \multicolumn{1}{|c|}{ Tratamiento } & $\begin{array}{c}\text { Afectación capacidades intelectivas } \\
\text { y volitivas }\end{array}$ & N.o \\
\hline Con tratamiento & Ninguna-Leve & 5 \\
\hline Sin tratamiento & Ninguna-Leve \\
& Grave-Anulación & 7 \\
\hline No especifica & Ninguna-Leve & 8 \\
\hline
\end{tabular}

En cuanto al consumo de drogas, la comorbilidad con la esquizofrenia puede llegar hasta el $50 \%$. Solamente se reflejan en las sentencias doce ( $n-5,8,10,13,14,16,17,21,26,28$, 33 y 34) casos de los treinta y cuatro estudiados, todos ellos afirmativos en cuanto a dicho consumo. Esto ya representa una elevada tasa de coexistencia entre la psicosis y el abuso de sustancias. Sin embargo, se trata también de una cuestión de suma importancia, que agrava las conductas violentas no solo en casos de enfermos mentales sino también en la población general. Por ello, debería reflejarse en la doctrina judicial, en cada uno de los casos, si dicha comorbilidad existía o no en el momento de la comisión del delito.

Los trastornos de la personalidad solo aparecen en cuatro sujetos, lo que no quiere decir que no sea un importante predictor de violencia, sino que no se pueden sacar conclusiones con tan pocos datos. Sería conveniente que las sentencias especificaran, al menos, la ausencia de este trastorno.

Todas estas variables predictoras de violencia en pacientes esquizofrénicos coinciden con las recogidas por Esbec y Echeburúa (2016) en su revisión. Estos autores destacaron como las más importantes el consumo de drogas, la ausencia de tratamiento y la presencia de trastornos de la personalidad. También el magistrado Echarri Casi señaló el incumplimiento terapéutico y el consumo de drogas como los factores más notables. Obviando la amplia mayoría obtenida por las variables sexo masculino y esquizofrenia de tipo paranoide, el abu- 
so de sustancias y la falta de tratamiento aparecen en un número muy significativo de los casos, respaldando las informaciones aportadas por los profesionales citados.

A pesar de los casos sin especificar, se puede concluir que hay un cierto reflejo de los factores de riesgo expuestos en el marco teórico en la jurisprudencia, y que dichos factores contribuyen al aumento de la comisión delictiva en pacientes con esquizofrenia. En orden de mayor a menor presencia, estas variables predictoras serían: sexo masculino, esquizofrenia paranoide, incumplimiento terapéutico, consumo de drogas y coexistencia de un trastorno de la personalidad. Se confirma por tanto la primera hipótesis planteada en este trabajo.

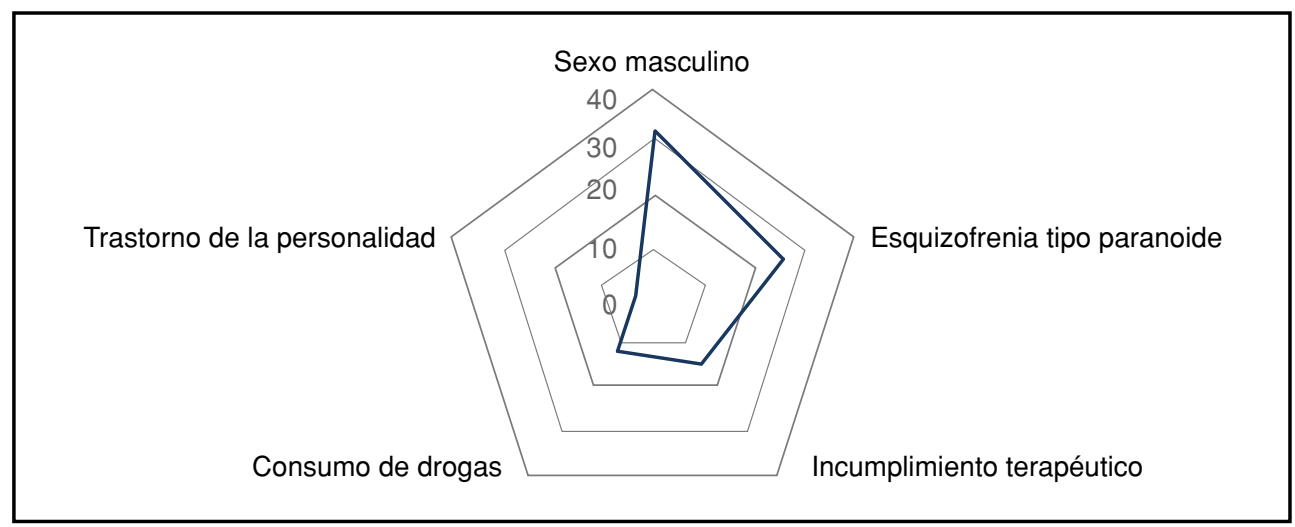

Figura 9. Presencia de los factores de riesgo analizados.

Es importante en este punto destacar la postura del magistrado Echarri acerca de la falta de información en muchas de las sentencias revisadas. Afirma que, concurran o no los factores estudiados, los jueces y tribunales solamente harán mención en sus sentencias de aquellos que hayan sido relevantes para la causa penal. El resto de dichos factores se encontrarían igualmente incluidos en los informes periciales.

En segundo lugar, se observa que hay un número considerable de casos en los que no existió nexo causal entre la psicosis del sujeto y el delito cometido, así como de ocasiones en las que el tribunal sentenciador no aprecia eximente ni atenuantes de la responsabilidad penal.

Estos resultados guardan relación con la afectación de las capacidades intelectivas y volitivas que la esquizofrenia pudiera producir en el paciente. Es evidente que en muchas ocasiones esta enfermedad incide en mayor o menor medida en la voluntad y pensamiento de quien la padece. De hecho, se observa que en todos los casos en los que dichas capacidades se encontraban completamente anuladas, el Tribunal Supremo optó por la aplicación de la eximente completa del artículo 20.1 del Código Penal, mientras que si se encontraban afectadas de forma grave, se aplicó la eximente incompleta del artículo 21.1. Por último, se optó por la atenuante analógica del artículo 21.7 cuando esta afectación fue leve. En el resto de casos donde no existió nexo causal, el Alto Tribunal no aplicó ninguna circunstancia modificativa de la responsabilidad. 
Tabla 3. Criterios seguidos por el Tribunal Supremo en cuanto a imputabilidad

\begin{tabular}{|l|c|}
\hline \multicolumn{1}{|c|}{$\begin{array}{c}\text { Afectación capacidades } \\
\text { intelectivas y volitivas }\end{array}$} & $\begin{array}{c}\text { Circunstancia modificativa } \\
\text { de la responsabilidad }\end{array}$ \\
\hline Anulación & Eximente completa del 20.1 \\
\hline Grave & Eximente incompleta del 21.1 \\
\hline Leve & Atenuante analógica del 21.7 \\
\hline No & No \\
\hline
\end{tabular}

Se ve, por tanto, que la jurisprudencia ha tenido que establecer una doctrina para tratar al menos las cuatro posibilidades planteadas de manera diferenciada. Además, hay un elevado número de casos (11) en los que el delito no presentaba nexo causal alguno con la enfermedad mental. Queda entonces claro que las personas con esquizofrenia, por un lado, no siempre delinquen con una plena afectación de sus capacidades, sino que estas se encuentran alteradas en distinto grado, y, por otro, que en algunas ocasiones sus actos delictivos nada tienen que ver con su enfermedad. Destacan sobre todo los 6 casos citados anteriormente en los que no existía tratamiento y no hubo ningún tipo de afectación de las capacidades del sujeto, lo que refuerza aún más esta última idea.

Esta última afirmación coincide con lo planteado por Esbec (2005) y con la opinión del propio magistrado de la Audiencia Nacional entrevistado en este trabajo. Quedarían duplicados, además, los criterios jurisprudenciales establecidos por Esbec y Echeburúa (2016) en su revisión de sentencias. Cabe destacar la respuesta de dicho juez acerca de la idoneidad de estos criterios doctrinales. Afirma que se irán modificando a medida que avance la medicina, ya que esta última, en estos casos, siempre debe ir por encima del Derecho Penal.

El estudio que se ha hecho del tratamiento jurisprudencial y del nexo causal en estos 34 casos lleva a concluir que, actualmente, en el sistema judicial español, y al contrario de lo que ocurría antiguamente, el diagnóstico de esquizofrenia, por sí mismo, no conlleva el decreto automático de la inimputabilidad del acusado. De esta manera la segunda hipótesis de este trabajo quedaría confirmada.

En tercer lugar, hay que destacar que el juez, en ningún caso, decretó el tratamiento ambulatorio involuntario como medida de seguridad no privativa de libertad. En todas las ocasiones en las que el acusado fue declarado inimputable o semiinimputable se acordó o bien la prisión para estos últimos, o bien el internamiento en un centro psiquiátrico para ambos.

Cierto es que, al tratarse de una medida de seguridad, posee un régimen mucho más flexible que el de las penas privativas de libertad. Esto significa que puede ser suspendida, sustituida por otra e incluso cesada en el caso de que desaparezca la peligrosidad del sujeto (art. 97 CP). Por lo tanto, aquellos casos en los que se decretó en un principio el internamiento en centro psiquiátrico podrían haber cambiado a un tratamiento ambulatorio involuntario, aunque no sea posible conocer esta cuestión con la mera revisión de sentencias. Sin embargo, como afirma el magistrado Echarri, el tratamiento forzado en régimen de libertad no sería factible. Al estar el individuo interno, este se encuentra bajo un régimen de especial protección por parte del Estado y, en consecuencia, sí que puede ser obligado a tratarse. Al quedar en libertad, dicho régimen ya no se aplica, y por tanto no se puede tratar a un paciente 
en contra de su voluntad. Y todo ello a pesar de que el Código Penal (art. 106.1 k)) recoge la obligación de someterse a tratamiento médico como medida dentro de la libertad vigilada.

En cualquier caso, se trata de un tema que carece de una legislación específica tanto en el ámbito civil como penal, en especial en este último. De hecho, según afirma este magistrado, el legislador penal no ha establecido ni siquiera la consecuencia que tendría el incumplimiento de una medida de este tipo en caso de que llegara a aplicarse, más allá del delito de quebrantamiento de medida de seguridad. No sería factible en este caso sustituir la medida incumplida por una más restrictiva e incluso privativa de libertad, ya que se estaría actuando en contra de la naturaleza del fallo dictado.

Se ve, por tanto, que ante la inseguridad jurídica existente sobre el tratamiento ambulatorio involuntario en el Derecho Penal, los jueces y tribunales optan siempre en estos casos por medidas de seguridad privativas de libertad, esto es, el internamiento en un centro psiquiátrico o médico adecuado.

Además de las tres cuestiones analizadas hasta ahora, se discutirán otras como la naturaleza de las víctimas o el diagnóstico que se hace de la psicosis de los acusados.

En cuanto a la primera de ellas, en principio se puede observar que la mayoría de las víctimas no eran del entorno del agresor. Sin embargo, es necesario hacer una puntualización, ya que no todos los delitos tienen como víctimas a personas concretas, o directamente protegen un bien jurídico de carácter no personal. Quedarían, por tanto, descartados aquellos ilícitos que no son de esta naturaleza, como los relativos a la salud pública, falsedad documental, apropiación indebida, cohecho, abuso de funciones, revelación de secretos, estafas, incendios y conducción temeraria. De esta manera, se obtendría que en 10 ocasiones las víctimas no tendrían ningún tipo de relación con su agresor, frente a 15 casos en los que esta sí existía, lo que representaría un $60 \%$ del total.

Figura 10. Víctimas del entorno del agresor (delitos contra las personas).

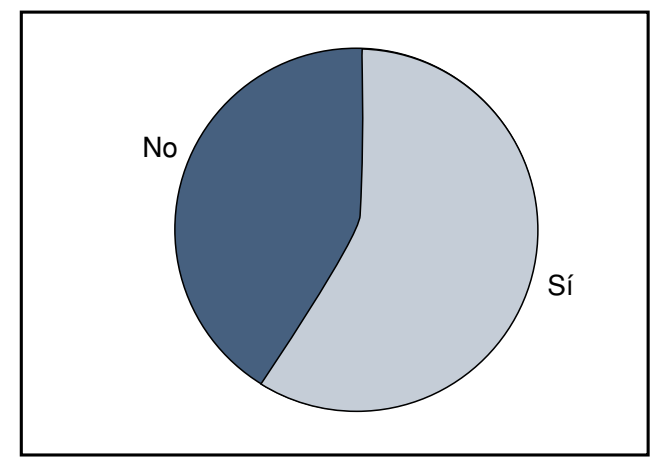

Este resultado encaja dentro del intervalo de entre el $50 \%$ y el $60 \%$ establecido por Joyal et al. (2004) para los casos en los que las víctimas pertenecían al entorno de un agresor que padecía una enfermedad mental grave. Por tanto, estos últimos resultados quedarían confirmados en esta revisión.

En cuanto a los tipos de esquizofrenia con que se han diagnosticado a los acusados, destaca el hecho de que hasta la última sentencia revisada del año 2017 esta enfermedad se seguía catalogando en subtipos, aunque esta modalidad diagnóstica fue eliminada por el DSM-V publicado en 2013. A pesar de ello, la imputabilidad del acusado se establece en fun- 
ción de la afectación de sus capacidades y del nexo causal, por lo que diagnosticar en base al DSM-IV o al DSM-V no debería suponer diferencia alguna. El magistrado Fermín Javier Echarri Casi señala que, se use uno u otro tipo de valoración psiquiátrica, lo importante es si de ella se puede extraer alguna consecuencia jurídica. Cabría la posibilidad, por ejemplo, de que alguna de las partes incorporara un dictamen pericial distinto que intentara desacreditar al primero en base a lo obsoleto de su diagnóstico.

\section{Conclusiones}

Como se puede apreciar tras la lectura de este trabajo, se han confirmado todas las hipótesis planteadas en el mismo. Se presentan a continuación las conclusiones extraídas:

1. Existe un reflejo de los factores de riesgo de violencia en esquizofrenia tanto en las treinta y cuatro sentencias del Tribunal Supremo como en las treinta y nueve sentencias de primera y segunda instancia estudiadas. Estas variables predictoras han sido, en orden de mayor a menor presencia, el sexo masculino, la esquizofrenia paranoide, la ausencia de tratamiento, el consumo de drogas y la concurrencia de un trastorno de la personalidad. Este último factor aparece en un número muy poco significativo. Cierto es que en muchos de los casos falta información sobre estos factores, en especial en el caso de la presencia o no de tratamiento en el momento de los hechos y del abuso de sustancias. Haría falta tener acceso a los expedientes médicos y a los informes periciales relativos a cada proceso penal para completar la información. A pesar de ello, con los datos obtenidos, se puede confirmar que las citadas variables suponen un incremento del riesgo de comisión delictiva por parte de las personas que padecen esquizofrenia.

2. Por otro lado, del análisis jurisprudencial llevado a cabo se desprenden dos cuestiones. En primer lugar, existen casos en los que no hubo ningún tipo de nexo causal entre el padecimiento de esquizofrenia y el delito cometido. En segundo lugar, en aquellos casos en los que dicho nexo sí existió, la afectación de las capacidades volitivas e intelectivas producida por esta enfermedad varió entre la levedad y la completa anulación. En función de esta última cuestión, el tribunal Supremo aplicó la eximente completa del artículo 20.1 del Código Penal cuando esta afectación fue plena, la eximente incompleta del artículo 21.1 cuando fue grave y la atenuante analógica del artículo 21.7 cuando fue leve. Esto permite concluir que, actualmente, en el sistema judicial español, y al contrario de lo que ocurría antiguamente, el diagnóstico de esquizofrenia, por sí mismo, no conlleva el decreto automático de la inimputabilidad del acusado.

3. Finalmente, se aprecia que en ninguna de las sentencias revisadas se aplicó el tratamiento ambulatorio involuntario como medida de seguridad no privativa de libertad. Se trata en este caso de un tema muy controvertido y sobre el que no hay seguridad jurídica, especialmente en el Derecho Penal. Como se ha mencionado en este trabajo, no queda claro de qué manera se podría subsanar el incumplimiento de someterse a tratamiento médico externo, más allá del posible delito de quebrantamiento de medida de seguridad.

Los resultados de esta investigación pretenden aportar un valor científico y teórico al tema de la violencia y la delincuencia en las personas que padecen esquizofrenia. Queda claro que 
estos individuos se ven envueltos en numerosas ocasiones por factores que incrementan el riesgo de dichas conductas, aunque no siempre sus comportamientos se deriven del padecimiento de la enfermedad. Y también que, actualmente, no existe una legislación suficiente en el ámbito penal para abordar la falta de tratamiento en aquellos sujetos que se hallen cumpliendo una medida de seguridad en libertad.

\section{Bibliografía}

American Psychiatric Association (1999). DSM-IV: Diagnostic and statistical manual of mental disorders (4th ed., 9th printing.). Washington: American Psychiatric Association.

American Psychiatric Association (2000). "Directrices para la práctica clínica en el tratamiento de pacientes con esquizofrenia», Autoevaluación y actualización en psiquiatría. Esquizofrenia y otros trastornos psicóticos, 1-91.

American Psychiatric Association (2013). «Highlights of Changes from DSM-IV-TR to DSM-5»,American Psychiatric Publishing, 1-19.

American Psychiatric Association (2014). Manual diagnóstico y estadístico de los trastornos mentales (DSM-5), 5. a ed., Madrid: Editorial Médica Panamericana.

Angermeyer, M. C. y Matschinger, H. (1995). «Violent attacks on public figures by persons suffering from psychiatric disorders. Their effect on the social distance towards the mentally ill», Eur Arch Psychiatry Clin Neurosci, 245: 159-64.

Arbach, K. y Pueyo, A. A. (2007). «Valoración del riesgo de violencia en enfermos mentales con el HCR20", Papeles del Psicólogo, 28 (3): 174-186.

Arseneault, L., Cannon, M., Poulton, R., Murray, R., Caspi, A. y Moffit, T. E. (2002). «Cannabis use in adolescence and risk for adult psychosis: Iongitudinal prospective study», British Medical Journal, 325: $1212-1213$.

Arseneault, L., Moffitt, T. E., Caspi, A., Taylor, T. J. y Silva, P. A. (2000). «Mental disorders and violence in a total birth cohort: results from the Dunedin Study», Archives of General Psychiatry, 57: 970-986.

Baldwin, P., Browne, D. y Scully, P. J. (2005). «Epidemiology of first-episode psychosis: Illustrating the challenges across Diagnostic boundaries through the Cavan-Monagan study at 8 years», Schizophrenia Bulletin, 31 (3): 624-38.

Bourget, D., el-Guebaly, N. y Atkinson, M. J. (2002). «Assessing and managing violent patients», Bulletin of Can Psychiatr Association, 34: 25-27.

Campbell, J. (1994). «Taking issue: putting violence in context», Hospital and Community Psychiatry, 45: 633.

Carrasco, J. J. y Maza, J. M. (2010). Tratado de psiquiatría legal y forense. 4. ${ }^{a}$ ed., Madrid: La Ley Actualidad.

Código Penal Español. Boletín Oficial del Estado. Última actualización del 14 de diciembre de 2017.

Corominas, M., Roncero, C., Bruguera, E. y Casas, M. (2007). "Sistema dopaminérgico y adicciones", Revista de Neurología, 44 (1): 23-31.

Diwan, A., Castine, M., Pomerleau, C. S., Meador-Woodruff, J. H. y Dalack, G.W. (1998). «Differential prevalence of cigarette smoking in patients with schizophrenic vs. mood disorders", Schizophrenia Research, 33: 113-8.

Echeburúa, E. y Loinaz, I. (2011). «Violencia y trastornos mentales», Violencia y psicología comunitaria. Aspectos psicosociales, clínicos y legales, Granada: Comares, 1-22.

Esbec, E. (2005). «Violencia y Trastorno mental», Cuadernos de Derecho Judicial, 8: 57-154.

Esbec, E. y Echeburúa, E. (2016). «Violencia y esquizofrenia: un análisis clínico-forense», Anuario de psicología jurídica, 26: 70-79

Fazel, S. y Danesh, J. (2002). «Serious mental disorder in 23000 prisoners: a systematic review of 26 surveys", The Lancet, 359: 545-550.

Fazel, S., Gulati, G., Linsell, L., Geddes, J. R. y Grann, M. (2009). «Schizophrenia and Violence: Systematic Review and Meta-Analysis», PLoS Medicine, 6 (8): e1000120. 
Goldner, E., Hsu, L., Waraich, P. y Somers, J. (2002). «Prevalence and incidence studies of schizophrenic disorders: a systematic review of the literature», Canadian Journal of Psychiatry, 47 (9): 833-843.

Gómez Jara, M. y Gómez Marichalar, N. (2009). «Prescripción de medicamentos», Consultas en psiquiatría legal, 129-138. Barcelona: Atelier.

Green, A. I. (2005). "Schizophrenia and comorbid substance use disorder: effects of antipsychotics», Journal of Clinical Psychiatry, 66 (Suppl 6): 21-26.

Green, A. I. (2006). «Treatment of schizophrenia and comorbid substance abuse: pharmacologic approaches", Journal of Clinical Psychiatry, 67 (Suppl 7): 31-35.

Hiday V. A. (1995). «The social context of mental illness and violence», Journal of Health and Social Behavior, 36: 122-137.

Hiday, V. A., Swartz, M. S., Swanson, J. W., Borum, R. y Wagner, H. (1999). "Criminal victimization of persons with severe mental illness», Psychiatric Services, 50: 62-68.

Ho, A. P., Tsuang, J. W., Liberman, R. P., Wang, R., Wilkins, J. N., Eckman, T.A. y Shaner, A. (1999). «Achieving effective treatment of patients with chronic psychotic illness and comorbid substance dependence», American Journal of Psychiatry, 156 (11): 1765-1770.

Horsfall, J., Cleary, M., Hunt, G. E. y Walter, G. (2009). «Psychosocial treatments for people with co-ocurring severe mental illnesses and substance use disorders (dual diagnosis): a review of empirical evidence", Harvard Review of Psychiatry, 17 (1): 24-34.

Jerrell, J. M. y Ridgely, M. S. (1995). "Comparative effectiveness of three approaches to serving people with severe mental illness and substance use disorders", Journal of Nervous and Mental Disease, 183 (9): 566-76.

Jockers-Scherubl, Wolf, T., Radzei, N., Schalttmann, P., Rentzsch, J., Gómez-Carrillo, A. y Kuhl, K. (2007). "Cannabis induces different cognitive changes in schizophrenic patients and in healthy controls", Progress in NeuroPsychopharmacology and Biological Psychiatry, 31 (5): 1054-1063.

Joyal, C. C., Putkonen, A., Paavola, P. y Tiihonen, J. (2004). «Characteristics and circumstances of homicidal acts committed by offenders with schizophrenia», Psychological Medicine, 34 (3): 433-442.

Kendler, K. S. y Diehl, S. R. (1995). "Schizophrenia: Genetics», Comprehensive Textbook of Psychiatry, 6. ${ }^{\text {a }}$ ed., vol I, 942-957.

Kosten, T. A. (1997). «Enhanced neurobehavioral effects of cocaine with chronic neuroleptic exposure in rats», Schizophrenia Bulletin, 23 (2): 203-213.

Krystal, J. H., D'Souza, D. C., Madonick, S. y Petrakis, I. L. (1999). «Toward a rational pharmacotherapy of comorbid substance abuse in schizophrenia patients», Schizophrenia Research, 35 Suppl: 35-49.

Ley de Enjuiciamiento Civil. Boletín Oficial del Estado. Última actualización del 4 de noviembre de 2017.

Ley de Enjuiciamiento Criminal. Boletín Oficial del Estado. Última actualización del 6 de octubre de 2015.

Lysaker, P. H., Bell, M. D., Bioty, S. M. y Zito, W. S. (1997). "Cognitive impairment and substance abuse history as predictors of the temporal stability of negative symptoms in schizophrenia», Journal of Nervous and Mental Disease, 185 (1): 21-26.

Martínez, J. M., Gurpegui, M., Díaz, F. J. y de León, J. (2004). «Tabaco y esquizofrenia», Monografía Tabaco, vol. 16. Supl. 2. 177-190.

McGrath, J., Saha, S., Welham, J., El Saadi, O., MacCauley, C. y Chant, D. (2004). «A systematic review of the incidence of schizophrenia: the distribution of rates and influence of sex, urbanicity, migrant status and methodology", BMC Medicine, 2, 13.

Molina, J. (2013). «Trastornos psicóticos. Esquizofrenia (1): subtipos clínicos, cursos evolutivos y tratamiento", Tratado de medicina legal y ciencias forenses, vol. V, Psiquiatría legal y forense.

Morera, B., Hueso, V. y Martínez, L. (2001). «Conductas violentas y enfermedad mental: predicción y abordaje en pacientes hospitalizados", Archivos de Psiquiatría, 64 (2): 137-154.

Mortensen, P. B., Pederson, C. B. y Westergaard, T. (1999). «Effects of family history and place and season of birth on the risk of schizophrenia», N Engl J Med, 340, 603-608.

Mueser, K. T., Drake, R. E. y Wallach, M. A. (1998). «Dual diagnosis: a review of etiological theories», Addictive Behaviors, 23 (6): 717-734.

Negrete, J. C. (2010) «Introducción», en Szerman, N. et al. (eds.), Patología dual en esquizofrenia. Opciones terapéuticas, 19-24. Barcelona: Editorial Glosa. 
Niechoff, D. (1999). The biology of violence: how understanding the brain, behavior and environment can break the vicious circle of aggression. New York: Free Press.

Noordsy, D. L. y Green, A. I. (2003). «Pharmacotherapy for schizophrenia and co-occurring substance use disorders", Current Psychiatry Reports, 5: 340-346.

Pescosolido, B. A., Monahan, J., Link. B. G., Stueve, A. y Kikuzawa, S. (1999). «The public's view of the competence, dangerousness, and need for legal coercion of persons with mental health problems", America Journal Public Health, 89: 1339-1345.

Potvin, S., Briand, C., Prouteau, A., Bouchard, R., Lipp, O., Lalonde, P. y Stip, E. (2005). «CANTAB explicit memory is less impaired in addicted schizophrenia patients", Brain and Cognition, 59: 38-42.

Potvin, S., Sepehry, A. y Stip E. (2007). «Meta-analysis of depressive symptoms in dual-diagnosis schizophrenia», Australian \& New Zealand Journal of Psychiatry, 41: 792-799.

Ruiz-Irondo, M., Salaberría, K., Echeburúa, E. (2013). «Análisis y tratamiento psicológico de la esquizofrenia en función de los estadios clínicos», Actas Españolas de Psiquiatría, 41: 52-59.

Saiz, J., de la Vega, D. y Sánchez, P. (2010). «Bases Neurobiológicas de la Esquizofrenia», Clínica y Salud, 21 (3): 235-254.

Silvestri, S., Negrete, J. C., Seeman, M., Shammi, C. M. y Seeman, P. (2004). «Does nicotine affect D2 receptor upregulation? A case-control study», Acta Psychiatr Scand, 109 (4): 312317.

Stuart, H. (2003). «Violence and mental illness: an overview», World Psychiatry, 2: 121-124.

Swanson, J. W., Swartz, M. y Van Dorn, R. (2006). «A National Study of Violent Behavior in Persons With Schizophrenia», Archives of General Psychiatry, 63: 490-499.

Tálamo, A., Centorrino, F., Tondo, L., Dimitri, A., Hennen, J. y Baldessarini, R. (2006). «Comorbid substance-use in schizophrenia: relation to positive and negative symptoms", Schizophrenia Research, 86 (1-3): 251-255.

Tiihonen, J., Isohanni, M., Räsänen, P., Koiranen, M. y Moring, J. (1997). «Specific major mental disorders and criminality: A 26-year prospective study of the 1966 northern Finland birth cohort», The American Journal of Psychiatry, 154 (6): 840-845.

Torre J., de la (1999). «La responsabilidad penal en las psicopatologías: valoraciones judiciales y jurisprudenciales", Estudios de Psicología, 63-64: 163-173.

Vicente, N., Díaz, H. y Ochoa, E. (2001). «Consumo de sustancias en pacientes con esquizofrenia», Psiquiatría.com.

Wessely, S. (1997). «The epidemiology of crime, violence and schizophrenia», British Journal of Psychiatry, 170 (Suppl. 32): 8-11.

Xie, H., McHugo, G. J., Helmstetter, B. S. y Drake, R. E. (2005). «Three-year recovery outcomes for long-term patients with co-occurring schizophrenic and substance use disorders», Schizophrenia Research, 75: 337-48. 


\section{Anexos}

Tabla 4. Sentencias del Tribunal Supremo y sentencias de 1. y 2. ${ }^{a}$ instancia

\begin{tabular}{|c|c|c|c|}
\hline N.o & $\begin{array}{l}\text { Sentencias } \\
\text { 1. }{ }^{\mathrm{a}} \text { instancia }\end{array}$ & $\begin{array}{l}\text { Sentencias } \\
\text { 2. }{ }^{\text {a }} \text { instancia }\end{array}$ & $\begin{array}{c}\text { Sentencias } \\
\text { Tribunal Supremo }\end{array}$ \\
\hline 1 & SAP Madrid 01/10/2007 & & $27 / 11 / 2008$ \\
\hline 2 & SAP Lugo 10/12/2007 & & $26 / 12 / 2008$ \\
\hline 3 & SAP Asturias 16/10/2008 & & $17 / 02 / 2009$ \\
\hline 4 & SAP Lleida 30/04/2008 & & $16 / 03 / 2009$ \\
\hline 5 & SAP Huelva 24/09/2007 & & $01 / 04 / 2009$ \\
\hline 6 & SAP Cuenca 19/12/2008 & TSJ Cast.-La Mancha 06/03/2009 & $14 / 07 / 2009$ \\
\hline 7 & SAP Las Palmas 31/03/2009 & & $10 / 12 / 2009$ \\
\hline 8 & SAP Málaga 25/05/2009 & & 07/03/2010 \\
\hline 9 & SAP Valladolid 01/02/2010 & & $02 / 11 / 2010$ \\
\hline 10 & SAP Madrid 14/04/2010 & & $21 / 12 / 2010$ \\
\hline 11 & SAP Barcelona 31/05/2010 & & $17 / 02 / 2011$ \\
\hline 12 & SAP Madrid 07/06/2010 & & $30 / 03 / 2011$ \\
\hline 13 & SAP Madrid 31/05/2010 & & $14 / 04 / 2011$ \\
\hline 14 & SAP Barcelona 30/11/2009 & TSJ Cataluña 07/09/2010 & $18 / 05 / 2011$ \\
\hline 15 & SAP Sevilla 15/10/2020 & & $25 / 05 / 2011$ \\
\hline 16 & SAP Santander $17 / 07 / 2010$ & & $13 / 06 / 2011$ \\
\hline 17 & SAP Barcelona 08/02/2011 & & $16 / 11 / 2011$ \\
\hline 18 & SAP Barcelona 25/04/2012 & & $20 / 03 / 2013$ \\
\hline 19 & SAP Barcelona 30/07/2012 & & $22 / 10 / 2013$ \\
\hline 20 & SAP Madrid 27/11/2012 & & $30 / 10 / 2013$ \\
\hline 21 & SAP Cádiz 25/07/2013 & & $12 / 03 / 2014$ \\
\hline
\end{tabular}


Tabla 4. Sentencias del Tribunal Supremo y sentencias de $1 .{ }^{a}$ y $2 .^{\underline{a}}$ instancia (Cont.)

\begin{tabular}{|c|c|c|c|}
\hline 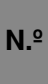 & $\begin{array}{l}\text { Sentencias } \\
\text { 1. }{ }^{\text {a }} \text { instancia }\end{array}$ & $\begin{array}{l}\text { Sentencias } \\
\text { 2. instancia }\end{array}$ & $\begin{array}{l}\text { Sentencias } \\
\text { Tribunal Supremo }\end{array}$ \\
\hline 22 & SAP Baleares 18/04/2013 & & 06/05/2014 \\
\hline 23 & SAP Badajoz 23/10/2013 & & $20 / 09 / 2014$ \\
\hline 24 & SAP Barcelona 05/02/2014 & & $05 / 11 / 2014$ \\
\hline 25 & SAP Pontevedra 19/11/2013 & TSJ Galicia 12/05/2014 & $20 / 01 / 2015$ \\
\hline 26 & SAP Barcelona 23/04/2014 & & 03/03/2015 \\
\hline 27 & SAP Málaga 27/02/2015 & & $18 / 11 / 2015$ \\
\hline 28 & SAP Ourense $24 / 07 / 2015$ & & $20 / 04 / 2016$ \\
\hline 29 & SAP Castellón 08/01/2016 & & $30 / 09 / 2016$ \\
\hline 30 & SAP Madrid 30/09/2015 & TSJ Madrid 18/02/2016 & $28 / 10 / 2016$ \\
\hline 31 & SAP Guipúzcoa 14/10/2016 & & $21 / 06 / 2017$ \\
\hline 32 & SAP Huesca 12/07/2016 & TSJ Aragón 21/12/2016 & $26 / 06 / 2017$ \\
\hline 33 & SAP Barcelona 12/12/2016 & & $24 / 10 / 2017$ \\
\hline 34 & SAP Barcelona 25/01/2017 & & $25 / 10 / 2017$ \\
\hline
\end{tabular}


Tabla 5. Delitos cometidos, circunstancias modificativas de la responsabilidad y medidas de seguridad o prisión

\begin{tabular}{|c|c|c|c|}
\hline N.․ & Delito & $\begin{array}{l}\text { Circunstancias } \\
\text { modificativas de la } \\
\text { responsabilidad }\end{array}$ & $\begin{array}{c}\text { Medidas } \\
\text { de seguridad/prisión }\end{array}$ \\
\hline 1 & Tentativa de asesinato & 20.1 & $\begin{array}{l}\text { Internamiento en centro } \\
\text { psiquiátrico penitenciario }\end{array}$ \\
\hline 2 & Tentativa de agresión sexual & No & Prisión \\
\hline 3 & Agresión sexual & 21.7 & Prisión \\
\hline 4 & Tentativa de homicidio & 21.1 & $\begin{array}{l}\text { Prisión e internamiento en } \\
\text { centro psiquiátrico }\end{array}$ \\
\hline 5 & Tentativa de homicidio & 21.1 & $\begin{array}{l}\text { Prisión sustituible por } \\
\text { internamiento en centro } \\
\text { psiquiátrico }\end{array}$ \\
\hline 6 & Homicidio imprudente y lesiones & 21.7 & Prisión \\
\hline 7 & Contra la salud pública & 21.1 & Prisión \\
\hline 8 & $\begin{array}{l}\text { Tentativa de homicidio y } \\
\text { amenazas }\end{array}$ & 21.1 & Prisión \\
\hline 9 & $\begin{array}{l}\text { Homicidio, lesiones y conducción } \\
\text { temeraria }\end{array}$ & 20.1 & $\begin{array}{l}\text { Internamiento en centro } \\
\text { psiquiátrico }\end{array}$ \\
\hline 10 & Asesinato y lesiones & 20.1 & $\begin{array}{l}\text { Internamiento en centro } \\
\text { psiquiátrico penitenciario }\end{array}$ \\
\hline 11 & Incendio y lesiones & 20.1 & $\begin{array}{l}\text { Internamiento en centro } \\
\text { psiquiátrico penitenciario }\end{array}$ \\
\hline 12 & Homicidio & 21.7 & Prisión \\
\hline 13 & Contra la salud pública & No & Prisión \\
\hline 14 & Asesinato y robo con fuerza & 21.2 & Prisión \\
\hline 15 & Tentativa de homicidio & 20.1 & $\begin{array}{l}\text { Internamiento en centro } \\
\text { penitenciario }\end{array}$ \\
\hline 16 & Contra la salud pública & No & Prisión \\
\hline 17 & Tentativa de homicidio & 21.1 & Prisión \\
\hline 18 & Lesiones & 21.7 & Prisión \\
\hline
\end{tabular}


Tabla 5. Delitos cometidos, circunstancias modificativas de la responsabilidad y medidas de seguridad o prisión (Cont.)

\begin{tabular}{|c|c|c|c|}
\hline N.으 & Delito & $\begin{array}{l}\text { Circunstancias } \\
\text { modificativas de la } \\
\text { responsabilidad }\end{array}$ & $\begin{array}{c}\text { Medidas } \\
\text { de seguridad/prisión }\end{array}$ \\
\hline 19 & $\begin{array}{l}\text { Falsedad documental y } \\
\text { apropiación indebida }\end{array}$ & 21.1 & $\begin{array}{l}\text { Internamiento en centro } \\
\text { médico o tratamiento } \\
\text { ambulatorio sin perjuicio de } \\
\text { prisión posterior }\end{array}$ \\
\hline 20 & Abuso sexual y detención ilegal & 21.1 & Prisión \\
\hline 21 & $\begin{array}{l}\text { Detención ilegal y robo con } \\
\text { violencia }\end{array}$ & No & Prisión \\
\hline 22 & $\begin{array}{l}\text { Atentado a la autoridad, cohecho, } \\
\text { abuso de funciones y revelación } \\
\text { de secretos }\end{array}$ & No & Prisión \\
\hline 23 & Falsedad documental y estafa & 21.7 & Prisión \\
\hline 24 & Asesinato y tentativa de homicidio & 20.1 & $\begin{array}{l}\text { Internamiento en centro } \\
\text { adecuado }\end{array}$ \\
\hline 25 & Incendio forestal & 21.1 & Prisión \\
\hline 26 & Robo con violencia e intimidación & No & Prisión \\
\hline 27 & Lesiones & 20.1 & $\begin{array}{c}\text { Internamiento en centro } \\
\text { adecuado }\end{array}$ \\
\hline 28 & Contra la salud pública & No & Absuelto \\
\hline 29 & Estafa & No & Prisión \\
\hline 30 & Asesinato y tentativa de asesinato & 20.1 & $\begin{array}{l}\text { Internamiento en centro } \\
\text { psiquiátrico }\end{array}$ \\
\hline 31 & Abuso sexual & No & Prisión \\
\hline 32 & Asesinato & No & Prisión \\
\hline 33 & Robo con fuerza & 21.7 & Prisión \\
\hline 34 & Asesinato & 20.1 & $\begin{array}{l}\text { Internamiento en centro } \\
\text { psiquiátrico penitenciario sin } \\
\text { perjuicio de cambio en el tipo } \\
\text { de centro psiquiátrico }\end{array}$ \\
\hline
\end{tabular}


Tabla 6. Tipo de esquizofrenia, comorbilidades y tratamiento

\begin{tabular}{|c|c|c|c|c|c|}
\hline N.․ & $\begin{array}{c}\text { Tipo } \\
\text { de } \\
\text { esquizofrenia }\end{array}$ & $\begin{array}{c}\text { Comorbilidad } \\
\text { drogas }\end{array}$ & $\begin{array}{l}\text { Comorbilidad } \\
\text { trastorno de la } \\
\text { personalidad }\end{array}$ & $\begin{array}{c}\text { Otra } \\
\text { comorbilidad }\end{array}$ & $\begin{array}{c}\text { En } \\
\text { tratamiento }\end{array}$ \\
\hline 1 & Paranoide & No especifica & No especifica & No especifica & No \\
\hline 2 & Residual & No especifica & Sí & No especifica & No especifica \\
\hline 3 & Paranoide & No especifica & No especifica & No especifica & Sí \\
\hline 4 & Paranoide & No especifica & No especifica & $\begin{array}{l}\text { Trastorno } \\
\text { delirante }\end{array}$ & No especifica \\
\hline 5 & Paranoide & Sí & No especifica & No especifica & No especifica \\
\hline 6 & No especifica & No especifica & No especifica & No especifica & Sí \\
\hline 7 & Paranoide & No especifica & No especifica & No especifica & No especifica \\
\hline 8 & Paranoide & Sí & No especifica & No especifica & No especifica \\
\hline 9 & Paranoide & No especifica & No especifica & No especifica & No \\
\hline 10 & Paranoide & Sí & Límite & $\begin{array}{l}\text { T. adaptativo } \\
\text { y disociativo }\end{array}$ & No especifica \\
\hline 11 & No especifica & No especifica & No especifica & No especifica & No especifica \\
\hline 12 & Paranoide & No especifica & No especifica & No especifica & Sí \\
\hline 13 & Paranoide & Sí & No especifica & No especifica & Sí \\
\hline 14 & Paranoide & Sí & No especifica & No especifica & No especifica \\
\hline 15 & Paranoide & No especifica & No especifica & No especifica & No especifica \\
\hline 16 & Paranoide & Sí & No especifica & No especifica & Sí \\
\hline 17 & Paranoide & Sí & No especifica & No especifica & No \\
\hline 18 & Paranoide & No especifica & No especifica & No especifica & No \\
\hline 19 & Residual & No especifica & No especifica & No especifica & No especifica \\
\hline
\end{tabular}

(Continúa) 
Tabla 6. Tipo de esquizofrenia, comorbilidades y tratamiento (Cont.)

\begin{tabular}{|c|c|c|c|c|c|}
\hline N.ㅇ & $\begin{array}{c}\text { Tipo } \\
\text { de } \\
\text { esquizofrenia }\end{array}$ & $\begin{array}{l}\text { Comorbilidad } \\
\text { drogas }\end{array}$ & $\begin{array}{l}\text { Comorbilidad } \\
\text { trastorno de la } \\
\text { personalidad }\end{array}$ & $\begin{array}{c}\text { Otra } \\
\text { comorbilidad }\end{array}$ & $\begin{array}{c}\text { En } \\
\text { tratamiento }\end{array}$ \\
\hline 20 & Paranoide & No especifica & No especifica & No especifica & No \\
\hline 21 & Indiferenciada & Sí & No especifica & No especifica & No \\
\hline 22 & Paranoide & No especifica & No especifica & No especifica & No especifica \\
\hline 23 & Paranoide & No especifica & No especifica & No especifica & No especifica \\
\hline 24 & Paranoide & No especifica & No especifica & No especifica & No \\
\hline 25 & Paranoide & No especifica & No especifica & Esquizoafectivo & No \\
\hline 26 & Paranoide & Sí & No especifica & No especifica & No \\
\hline 27 & Paranoide & No especifica & No especifica & No especifica & No \\
\hline 28 & Hebefrénica & Sí & No especifica & No especifica & No \\
\hline 29 & Paranoide & No especifica & No especifica & Depresión & No \\
\hline 30 & Paranoide & No especifica & No especifica & No especifica & No \\
\hline 31 & Paranoide & No especifica & No especifica & No especifica & No \\
\hline 32 & No especifica & No especifica & Esquizoide & No especifica & No \\
\hline 33 & Paranoide & Sí & No especifica & No especifica & No especifica \\
\hline 34 & Desorganizada & Sí & Antisocial & No especifica & No especifica \\
\hline
\end{tabular}


Tabla 7. Diagnósticos previos de esquizofrenia y comorbilidades

\begin{tabular}{|c|c|c|c|c|}
\hline N.. & $\begin{array}{l}\text { Diagnóstico } \\
\text { previo } \\
\text { esquizofrenia }\end{array}$ & $\begin{array}{l}\text { Diagnóstico } \\
\text { previo drogas }\end{array}$ & $\begin{array}{l}\text { Diagnóstico } \\
\text { previo trastorno } \\
\text { de la personalidad }\end{array}$ & $\begin{array}{l}\text { Diagnóstico } \\
\text { previo otras }\end{array}$ \\
\hline 1 & Sí & & & \\
\hline 2 & Sí & & Sí & \\
\hline 3 & Sí & & & \\
\hline 4 & Sí & & & Sí \\
\hline 5 & Sí & Sí & & \\
\hline 6 & Sí & & & \\
\hline 7 & Sí & & & \\
\hline 8 & Sí & Sí & & \\
\hline 9 & Sí & & & \\
\hline 10 & Sí & Sí & Sí & Sí \\
\hline 11 & Sí & & & \\
\hline 12 & Sí & & & \\
\hline 13 & Sí & Sí & & \\
\hline 14 & Sí & Sí & & \\
\hline 15 & Sí & & & \\
\hline 16 & Sí & Sí & & \\
\hline 17 & Sí & Sí & & \\
\hline 18 & No & & & \\
\hline 19 & Sí & & & \\
\hline 20 & Sí & & & \\
\hline 21 & No & No & & \\
\hline 22 & Sí & & & \\
\hline 23 & Sí & & & \\
\hline 24 & Sí & & & \\
\hline 25 & No & & & Sí \\
\hline 26 & No & No & & \\
\hline 27 & Sí & & & \\
\hline 28 & Sí & Sí & & \\
\hline 29 & No & & & Sí \\
\hline 30 & No & & & \\
\hline 31 & Sí & & & \\
\hline 32 & No & & Sí & \\
\hline 33 & Sí & Sí & & \\
\hline 34 & Sí & Sí & Sí & \\
\hline
\end{tabular}


Tabla 8. Afectación capacidades intelectivas y volitivas, nexo causal, víctima del entorno y sexo

\begin{tabular}{|c|c|c|c|c|}
\hline N.. & $\begin{array}{l}\text { Afectación capacidades } \\
\text { intelectivas y volitivas }\end{array}$ & Nexo causal & $\begin{array}{l}\text { Víctima } \\
\text { del entorno }\end{array}$ & Sexo \\
\hline 1 & Anulación & Sí & No & Masculino \\
\hline 2 & No & No & No & Masculino \\
\hline 3 & Leve & Sí & Sí & Masculino \\
\hline 4 & Grave & Sí & No & Masculino \\
\hline 5 & Grave & Sí & Sí & Masculino \\
\hline 6 & Leve & Sí & Sí & Masculino \\
\hline 7 & Grave & Sí & No & Masculino \\
\hline 8 & Grave & Sí & Sí & Masculino \\
\hline 9 & Anulación & Sí & No & Masculino \\
\hline 10 & Anulación & Sí & No & Femenino \\
\hline 11 & No especifica & No especifica & Sí & Masculino \\
\hline 12 & Leve & Sí & Sí & Masculino \\
\hline 13 & No & No & No & Masculino \\
\hline 14 & No & No & Sí & Masculino \\
\hline 15 & Anulación & Sí & Sí & Masculino \\
\hline 16 & No & No & No & Masculino \\
\hline 17 & Grave & Sí & Sí & Masculino \\
\hline 18 & Leve & Sí & Sí & Femenino \\
\hline 19 & Grave & Sí & No & Masculino \\
\hline 20 & Grave & Sí & Sí & Masculino \\
\hline 21 & No & No & No & Masculino \\
\hline 22 & No & No & No & Masculino \\
\hline 23 & Leve & Sí & No & Masculino \\
\hline 24 & Anulación & Sí & Sí & Masculino \\
\hline 25 & Grave & Sí & No & Masculino \\
\hline 26 & No & No & No & Masculino \\
\hline 27 & Anulación & Sí & No & Masculino \\
\hline 28 & No & No & No & Masculino \\
\hline 29 & No & No & No & Masculino \\
\hline 30 & Anulación & Sí & Sí & Masculino \\
\hline 31 & No & No & Sí & Masculino \\
\hline 32 & No & No & No & Masculino \\
\hline 33 & Leve & Sí & No & Masculino \\
\hline 34 & Anulación & Sí & Sí & Masculino \\
\hline
\end{tabular}

